This report was prepared as an acoount of wark sponsored by an agency af the United States Government. Neither the United States Government nor any agency thereof, nor any of their empioyees, makes any warranty, express or implied, or assumes any legal liability or responsibility for the accuracy, completencs, of usefulfess of any information, appatatus, product, or process disclosed, of represents that its use would not infringe privatsly owned rights. Reference herein to arty specific commercial product, pricess, or service by trade name, tradernark. masufacturer, or otherwise does not nocessarily constitule or imply its endorsement, recommendation, or favoring by the United States Government or any agency thereof. The views and opinions of authors expressed herein do not necessarily state or reflect thase of the United Stales Government or any agency theroot.

\title{
Characteristics of Low-q Disruptions in PBX
}

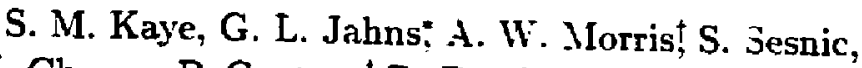 \\ K. Bol, M. Chance, P. Coutureł R. Fonck, G. Gamme' W. Heidbrink; \\ R. Kaita, H. Kugel, B. LeBlanc, J. Manickcim, \\ N. Ohyabu;, M. Okabayashi, M. Reusch, H. Takahashi \\ Princeton Plasma Physics Laboratory \\ Princeton, N.J. 08543
}

GA Technoloyies Inc., San Diego, Cal

†Belliol College, University of Oxford, U. K.

"Institut de Recherche d'Hydro-Queber, Canada 


\begin{abstract}
Absiract
At low- $q_{v}\left(2.3 \leq q_{\psi} \leq 4.5\right)$ in the Princeton Beta Experiment, the $\left(\beta_{t}\right\rangle$ limit is manifest as a hard disruption following the growth and sawtooth-like "crash" of a $\leq 25 \mathrm{kHz}$ precursor oscillation. The disruption, which occurs even in discharges with $\left\langle\beta_{e}\right\rangle$ well below the first stability regime boundary $\left(\simeq 2.5 \mu_{0} I_{p} / a B_{t}\right)$, follows the crash of this precursor mode either immediately or with a several msec delay, with the immediate dissuptions occurring in the discharges with $\left\langle\beta_{t}\right\rangle$ close to the first regime limit. The highest $\left\langle\beta_{t}\right\rangle$ discharges also exhibit the fastest growth times and the highest level of edge MHD activity. Associated with the precursor mode crash is a loss of up to $30 \%$ of the plasma energy; thus, for non-zero delay shots it is the crash and not the actual disruption that is the $\left\langle\beta_{t}\right\rangle$-limiting process. The delay period is interpreted as a period during which a locked mode, consisting of several tornidd components of comparable amplitude, grows. Because of the energy loss associated with the crash, the plasma gues rertically unstable during the delay period. The results of this study indicate that even within the relatively narrow low-qu operating space, there js a continuum in the characteristics of the low- $q_{\psi}$ distuptions with a primary dependence on the value of $\left\langle\theta_{\imath}\right\rangle$. While the ideal external kink instability may give rise to the growing uscillations that lead up to the ultimate disruption, the instabilities are weighted towards the edge only at the lowest- $g_{\psi}(\leq 3)$ and highest $\left\langle\beta_{t}\right\rangle$. At even slightly higher $q_{v}$, the oscillations are also seen, at the same frequency, in the interior of the plasma. The results further indicate that effects outside the scope of ideal MHD theory may play a significant role in low- $q_{\psi}$ disruptions.
\end{abstract}




\section{Introduction}

Discharges in the Princeton Beta Experiment (PBX), although achieving volume averaged $\left\langle\beta_{\mathrm{t}}\right\rangle$ values of up to $5.5 \%$, were limited to the first stability regime as parameterized by Troyon et a].[1] and Sykes[2]. In these works, the first regime stability limit is given by $\left\langle\beta_{t}\right\rangle=C_{\mu_{0}} I_{p} / a B_{l}$ where the constant of proportionality, $C$, is between 2.2 and 3.5 depending on whether the pressure profiles are optimized with respect to ideal kinks[1; or high-n ballooning?2]. This parametric expression is consistent with the $\left(\beta_{\ell}\right)$-limits observed in conventional tokamak operation|3]. In two earlier papers;4.51. we reported analyses of $P B X$ data that indicated the $n=1$ ideal external kink to be a mechanism responsible for the $\left(\beta_{\imath}\right\rangle$-limit in low-q $\left(q_{\psi} \leq 3\right)$ PBX discharges. Here, $q \psi$ is taken to be the NHD q-value at the $95 \%$ flux suriace (because of the occasional presence of a separatrix surface in the vacuum vessel).

The first PBX paper[4] addressed the global characteristics of the high$\left\langle\beta_{t}\right\rangle$ equilibrium and their relation to the $\left\langle\beta_{t}\right\rangle$-limits imposed by ideal MHD modes. The measured PBX pressure profiles and $\left(\beta_{k}\right\rangle$ valnes in the high- $\left\langle\beta_{k}\right\rangle$, low- $q_{\psi}(\leq 3)$ discharges were determined to be stable to high-n ballooning modes; for the measured profiles, the $\left(\beta_{t}\right)$ threshold for these nudes was approximately $9 \%$. However, the plasma equilibrium at $\left\langle\beta_{t}\right\rangle \simeq 5.5 \%$ was found to be marginally unstable to the $n=1$ ideal external kink for a conducting wall positioned at twice the plasma midplane half-width.

In the second PBX paper[5], a more detailed comparison was made be. tween some of the observed MHD phenomena and those expected from ideai MHD theory. Based on the calculated equilibrium for these discharges, the unstable eigenmode structure and the theoretically expected exiernal magnetic perturbations were determined using the PEST code[6]. Although comparisons between the relative amplitudes of the observed and calculated fluctuations generally showed agreement, more detailed agreement between the poloidal phases of the signals could be achieved only when nonideal MHD effects (e.g., the presence of a resistive plasma mantle) were taken into account. In addition, growth times of the disruption precursor mode were typically longer than expected from ideal MHD theory.

In this paper, which is a companion to the paper by Jahns et al.[5], we concentrate on the experimental detajls of the low-q disruptions and the precursor mode that leads up to the disruption. The data are from discharges 
with $q_{\psi} \leq 4.5$ that ended in a hard disruption regardless of the proximity to the first regime $\left\langle\beta_{t}\right\rangle$-limit. In particular, we will present data typifying two different disruption scenarios, one with the disruption immediately following the rapid growth of a precursor mode, and one which exhibits distinct phases; growth and "crash" of the precursor mode, a delay perind of several mser following the crash, and then the disruption. The observation of sawtoothlike crashes that could cause a large and rapid energy loss from the plasma was repurted previously[7,8], and in the latter paper it was recngnized that crashes with large enough energy loss $(>20 \%)$ inevitably led to a disruptive termisation of the discharge. Following the presentation of the disruption scenarios, we will present a statistical picture of the dependence of some of the identifiable disruption parameters on discharge characteristics. A large variation exists in the siructures and characteristics of the pre-distuption modes and events. The rariations form a continuum rather than discrete sets dependent on particular plasma parameters. Therefore, we will conclude that this continuum reflects more the different manifestations of one global mode rather than the consequences of different modes.

\section{PBX Experiment}

The Princeton Beta Experiment (PBX) is described in detail in Bol et al.4] and Okahayashi et al.'9l. The aim of the experiment was to explore high- $\left(\beta_{l}\right\rangle$ regimes in both the ñrst and second region of stability to high-n ballowning. To do this, the PDX (Princeton Divertor Experiment) was modified by moving one of the inside divertor coils to the vessel midplane to act as a "pusher" coil, providing the magnetic field component necessary to produce indented plasmas. The bean-shaped configuration is theoretically more stable to high-n ballooning and internal kinks because of the effestive outward shift of the magnetic flux surfaces and triangularity of internal flux surfaces, respective]y [10-12]. However, to ensure that these internal kinks ("fishbones") would not be a problem, two of the four beamlines were reoriented from a near-perpendicular injection angle $\left(R_{\text {tan }}=35 \mathrm{~cm}\right)$ to a sear-tangential one $\left(R_{t a n}-130 \mathrm{~cm}\right)$. A further modification of PDX was the addition of nickel-coated aluminum passive stabilizer plates on the top and bottom, which, along with an active feedback coil, suppressed the $n=0$ axisymmetric mode and maintained the plasma vertical position during normal plasma operation. 
PBX plasmas were produced with discharge parameters $B_{t}=0.7$ to $1.9 T, \bar{n}_{e}=1.5$ to $7.0 \times 10^{13} \mathrm{~cm}^{-3}, R=144$ to $153 \mathrm{~cm}, I_{p}=230$ to $600 \mathrm{kA}, a_{\text {mad }}$ (midplane half-width) $=30$ to $38 \mathrm{~cm}$, elongations of up to 1.8 , indentations of up to $22 \%$, and $q_{\psi}$ values down to $\simeq 2.2$. Here, indentation is defined as $d / 2 a^{*}$ where $d$ is the difference in major radial positions of the bean tip and the outer Hux surface at the midplane on the inboard side, and $2 a^{*}$ is the difference in major radial positions of the bean tip and outer flux surface at the midplane on the outboard side. The highest $\left\{\beta_{\ell}\right\rangle$ plasma discharges were obtained for the highest indentations, lowest $q_{\psi}$ 's, and highest plasma currents produced. To achieve these high plasma currents, the discharges were run with $i_{p} \geq 1.5 \mathrm{MA} / \mathrm{sec}$ in order to broaden the current profile and te) produce the indentation and elongation necessary to support this current. These plasmas, described in more detail in Bol et al.[A], were typically limited by the pusher coil or the top and bottom passive stabilizers, but sometimes were just barely diverted (i.e., x-points just inside the inboard stabilizer). The equilibrium flux contours for a high- $\left(\beta_{\ell}\right)$ discharge are shown in Fig. 1. Discharge characteristics for this shot were $\left\langle\beta_{t}\right\rangle=5.3 \%, I_{p}=570 \mathrm{kA}, B_{\mathrm{t}}=$ $0.9 \mathrm{~T}, \bar{n}_{e} \geq 5 \times 10^{13} \mathrm{~cm}^{-3}, q_{\psi}=3.0, \dot{I}_{p}=2 \mathrm{MA} / \mathrm{sec}$, and $P_{\text {inj }}=4.7 \mathrm{MW}$ of deuterium beams ( $\simeq 45 \mathrm{keV}$ ) into a hydrogen plasma. Note that although the entire separatrix surface remained inside the inboard stabilizer at this time, no L- to H-mode transition was observed for this shot. All shots with $\dot{l}_{p} \geq 1.5 \mathrm{M} / \mathrm{A} / \mathrm{sec}$ remained in the L-mode, regardless of the presence of a separatrix inside the vessel chamber. Also note from Fig. 1 the relative lack of shaping of the internal flux surfaces. This was due to insufficjent flexibility in the control system.

The principal diagnostics used in this study consist of magnetic pick-up loops, soft X-ray arrays, a fast diamagnetic loop, neutron scintillator, a fast charge-exchange neutral analyzers, and charge-exchange recombination spectruscopy. The magnetic pick-up loops, measuring magnetic perturbations, consist of a toruidal array of three in/out pairs of $B_{\theta}$ coils $\left(N A=0.015 \mathrm{~m}^{2}\right.$ turns) and a toroidal array of seven $B_{r}$ loops ( $N A=0.04 \mathrm{~m}^{2}-$ turns) for toroidal mode number (n) identification, and an eight probe poloidal array of $B_{\theta}$ coils $\left(N A=0.015 \mathrm{~m}^{2}-\right.$ turns $)$ for poloidal mode number $(\mathrm{m})$ information. The data acquisition systems of these arrays limited the frequency information to $\leq 20 \mathrm{kHz}$ for the $B_{\theta}$ coils and $\leq 50 \mathrm{kHz}$ for the $B_{\mathrm{r}}$ loops. One stand-alone $B_{\theta}$ coil provided frequency information up to $50 \mathrm{kHz}$. Since all of the fluctuations observed in this study had frequencies $\leq 25 \mathrm{kHz}$, and 
most of them had frequencies $\leq 20 \mathrm{kHz}$, the frequency limitation did not pose much of a restriction.

The soft X-ray (SXR) diagnostic consisted of a vertical array (15 diodes) and a horizontal array (21 diodes) of silicon surface barrier diodes. The vertical system had a fixed filter of $3 \mathrm{mil}$ Be, allowing sensitivity in the energy range of 2.2 to $25 \mathrm{keV}$, while the horizontal array had a variety of filters, but typically used a $0.5 \mathrm{mil}$ Be filter allowing sensjtivity in the 1.2 to $15 \mathrm{keV}$ range. The highest frequency bandwidth achievable by either system was $200 \mathrm{kHz}$. A high resolution diamagnetic loop was used to measure the displaced toroidal flux, which is related to the perpendjcular poloidal $\beta$. The diamagnetic loop and compensation loops were mounted inside the vessel, and eddy current effects were negligible for the present studies. Neutron measurements were made with an uncollimated plastic scintillator mounted just outside the vacuum vessel. Fast charge-exchange efflux measurements were made by a variable energy ( 5 to $90 \mathrm{keV}$ ), variable sightline $\left(R_{\text {tan }}=58\right.$ to $160 \mathrm{~cm}$ looking at co-circulating particles) compact neut ral analyzer. A more detailed description of these diagnostics can be found in Heidbrink et al. 13) and references therein. Finally, plasma rotation velocities were determined by measuring the Doppler shift of the $O^{8+}$ line with the scannable single-point PBX-CHERS diagnostic[14].

\section{Experimental Results}

\subsection{Overview of $P B X\left\langle\beta_{t}\right\rangle-q_{\psi}$ Operating Space}

In Fig. 2 are plotted the achieved $\left\langle\beta_{t}\right\rangle$ values versus the parameter $\beta_{c}=\mu_{0} J_{p} / a B_{t}$ for PBX discharges with indentations $\geq 5 \%$. The discharges are sorted according to whether they were disruptive or non-disruptive. The plasma is defined to be disruptive if a discharge terminating dissuption occurred during, or within 10 msec after, the maximum beam power phase for that discharge. There are several features to note in Fig. 2. The first is that the PBX operating space extended to $\beta_{c}$ values of up to 2.7 , in comparison to circular PDX plasmas which achieved $\beta_{c}$ values of only up to $1.0[15]$, and D-shaped DIII plasmas achieving higher values of $\beta_{c}$, up to 1.9[16]. Since $\beta_{c}$ reflects the average current density, the PBX results show that the indented plasmas were capable of $40 \%$ higher average current density than an elongated ( $\kappa=1.6$ ), but non-indented one (i.e., DIII[16]). Indeed, the high- 
est $\beta_{c}$ plasmas in PBX had $q_{\psi}$ values down to 2.2 , and $q_{c y l}$ values down to $\leq 1.0$, where $q_{c y l} \times(a)^{2} B_{t} / R I_{p},\langle a\rangle$ being the volume-averaged, or equivalent circular, minor radjus.

Of particular importance to low-q operation of tokamaks is the second feature of Fig. 2; whether a discharge disrupted was controlled not by the proximity to the first regime limit $\left(\left\langle\beta_{t}\right\rangle / \beta_{c}\right)$, but rather by the value of $\beta_{c}$ (or $\left.q_{w}\right)$. It is clear that practically all discharges with $\beta_{c} \geq 1.9$ were disruptive. The one exception was a pellet-fuelled discharge which disrupted outside the time window defining disruptive discharges by a few msec.

Below $\beta_{c}=1.9$, there were as many disruptive as non-disruptive discharges near the $\left\langle\beta_{t}\right\rangle$-limit. At the lowest $\beta_{c}$, most of the discharges, even those near the $\left(\beta_{t}\right)$-limit, were non-disruptive. These results differ from those of DIII. While $q_{\psi} \leq 3.5$ discharges on DIIl, as in PBX, were always found to disrupt regardless of $\left\langle\beta_{l}\right\rangle / \beta_{c}$, they were characterized by a $\left(\beta_{t}\right)$-limit that was also a disruptive limit even at higher $q_{\psi}[16]$. On the other hand, ASDEX, like PBX, could produce non-disruptive discharges at the $\left(\beta_{t}\right)$-limit for $q_{4} \geq 4.0 .[17]$

The disruption probability of a subset of the data shown in Fig. 2, for discharges with $q_{\psi} \leq 6.0$ and with indentations $>5 \%$, may be inferred from the histograms plotted in Fig. 3. In the figure, the data are grouped into bins of $\Delta q_{\psi}=0.2$, and shown are both the total number of discharges and the number of disruptive discharges within each bin. As $q_{\psi}$ decreases, the percentage of shots that disrupted increases. For instance, at $q_{\psi}=5,25 \%$ of the shots were disruptive, but the percentage jumps to $80 \%$ at $q_{\psi}=4$ and to almost $100 \%$ at $q_{\psi}=3$. The Jahns et al. [5] study concluded that the jump in disruption probability at integer $q_{\psi}$, specifically at $q_{\psi}=3$ in that study, was evidence for the global nature of the mode involved in the disruption. This paper will focus on the characteristics of the hard disruptions for discharges with $q_{\psi} \leq 4.5$, and search for the parameters, if any, that were associated with a discharge surviving at the lowest $q_{\psi}$ values. 
3.2. Discharge Evolution: Events Leading up to the Disruption

\subsubsection{Precursor Activity}

An overview of the two types of low-q disruption scenarios is shown in Fig. 4. The discharge in the left-hand panel was run with little $(\simeq 0.5$ $\mathrm{MA} / \mathrm{sec}$ ) current ramp, resulting in a relatively low plasma current of 375 $\mathrm{kA},\left\langle\beta_{\mathrm{t}}\right\rangle=3 \%$, and $q_{\psi}=4.5$ (the upper limit of the $q_{\psi}$ range for the data used in this study). By comparison, the discharge shown in the right-hand panel was run with a large current ramp rate $(1.8 \mathrm{MA} / \mathrm{sec})$, resulting in a high current of $600 \mathrm{kA},\left\langle\beta_{\mathrm{t}}\right\rangle=5.3 \%$, and $q_{\psi}=2.2$. Both discharges were hydrogen, and they were heated by $5 \mathrm{MW}$ of deuterium neutral beams. The Long-Sawtooth Mode, high- $\left(\boldsymbol{\beta}_{\boldsymbol{t}}\right)$ shots are described in more detail in Bol et al.[4].

The MHD activity leading up to the disruption in the two cases shown in Fig. 4 differed substantially, as can be seen most readily in the two lower graphs (outer midplane $\dot{B}_{\theta}$ and pear central SXR signal). In the higher- $q_{\psi}$ discharge, bursts of activity associated with sawteeth lasted from approximately 450 to $550 \mathrm{msec}$, and these were followed in time by repetitive bursts of MHD between 550 and 630 msec identified as fishbones. At approximately $635 \mathrm{msec}$, a large amplitude precursor oscillation grew in both the central SXR and the Mirnoy signals, and was followed by a "sawtuoth-like crash," which will be shown for a similar shot in more detai' later. From here on, we will refer to this sawtooth-like crash as the "pre-disruption event," or simply, "event." While a significant amount of energy was lost at the time of the event, the discharge did not terminate. In fact, although not shown in the figure, the plasma current remained unperturbed. There was a delay, in this case of about 10 msec, between the time of the event and the actual disruptive termination of the discharge at $647 \mathrm{msec}$. For this discharge, the frequency of the event precursor was approximately $5 \mathrm{kHz}$ both in the center (SXR) and outside the plasma (Mirnov probe). For all discharges studied, the center and edge (outside) frequencies were seen to be equal.

In contrast to the higher- $q_{w}$ shot, the lower-q: discharge exhibited a relatively low level of MHD activity up until several tens of msec before the disruption. Sawteeth were evident from 400 to $480 \mathrm{msec}$, but they are suppressed during the period of large current ramp ( $t \geq 480 \mathrm{msec}$ ). The period of no sawtooth, or little other MHD, activity lasted, in this case, for ap- 
proximately $100 \mathrm{msec}$. Some mapnetic activity appeared at $530 \mathrm{msec}$ with a characteristic frequency of $8 \mathrm{kHz}$ and $\frac{\bar{B}_{\theta}}{B_{\theta}} \simeq 0.5 \%$ at the position of the coil. Also present in this case, but not apparent in the figure, was a lower frequency mode at $1.6 \mathrm{kHz}$ concurrent with the $8 \mathrm{kHz}$ mode. Both frequencies exhibited an $n=1$ toroidal struct ure. The SXR array was sampling fast enough to detect either frequency component only from 520 to $555 \mathrm{msec}$, and during this time both modes were observed. For this lower- $q_{\psi}$ discharge, the growing disruption precursor event led directly into the plasma disruption; no delay period, as seen in the higher- $q_{\psi}$ shot, was evident.

An expanded view of the period leading up to the precursor and ultimate disruption for a shot with finite delay is shown in Fig. 5. Plasma parameters for this discharge were $I_{p}=510 \mathrm{kA}, i_{p}=1.9 \mathrm{MA} / \mathrm{sec}, q_{\psi}=3.0,\left\langle\beta_{i}\right\rangle=$ $3.1 \%$, and $\left(\beta_{t}\right) / \beta_{c}=1.5$. Plotted in the figure from the top are the displaced toroidal flux, $\Delta \Phi_{t}$, the neutron flux, the time-integrated Mirnov coil signal, $\dot{B}_{\theta}$, raw Mirnov coil signal, $\dot{B}_{\theta}$, and a near central chord from the vertically viewing SXR array. The discharge shown here is a different one than that shown in Fig. 4; however, the essential features of the MHD activity are the same. In this finite delay shot, a $14 \mathrm{kHz}$ signal grew on a time scale of $200 \mu$ sec just, prior to the event. Here, the growth time is taken to be the time for the oscillation to grow to its pre-disruption ampiitude from $1 / e$ of that amplitude. The peak-to-peak amplitude of the magnetic fluctuation just prior to the event was 9 Gauss, corresponding to $\frac{\tilde{B}_{\theta}}{B_{\theta}}=0.5 \%$ at the position of the coil (approximately $30 \mathrm{~cm}$ beyond the outer edge of the plasma and situated neat the outer vessel wall), where $B_{\theta}$ is the poloidal field at the coil. The total poloidal field reduction at this coil position due to the event was approximately 85 Gauss. As will be discussed, this change in poloidal field was position dependent, and it does not reflect a change in the total plasma current, which remained constant through the event and during the delay period.

The drop in the central SXK signal and neutron flux reflects the loss of plasma stored energy inferred from the drop in diamagnetic loop signal (top trace). The drop in tcroidal flux indicates a loss of approximately $30 \%$ of the plasma plus beam-stored energy at the time of the event. The drop in neutron flux at the event is $65 \%$, and it probably represents a combination of both a radial redistribution of fast ions into regions of lower thermal neutral 
density, and a decrease in production due to changes in plasma parameters at this time (e.g., shorter slowing down time due to reduced $T_{e}$ ) [13]. Bearninduced reactions dominated thermonuclear reactions under these conditions. Associated with the drop in neutron flux at the time of the event was a sharp increase in the flux of charge-exchange (c-x) neutrals from the plasma (not shown!. The increase in $c-x$ flux may indicate an actual increased loss of fast ions, their radial redistribution, or merely an increase in neutral density over the c-x sightline. The coincidence of the $c-x$ burst and the drop in neutrons lends itself more to the explanation of a radial redistribution, or actual increased loss, of fast ions at this time. The energy lost from the plasma due to the event was never recovered, and the displaced toroidal flux remained constant until the ultimate disruption approximately 2 msec after this pre-disruption event. It was this pre-disruption event, and not the disruption itself, that was the $\left\langle\beta_{t}\right\rangle$-limiting process at low- $q_{\psi}$ because of the significant loss of energy from the plasma.

An expanded view of the period of time just prior to the disruption in a zero delay shot is shown in Fig. 6. Here, all the energy was lost at the time of the event, as evidenced by the drop in displaced toroidal flux and soit $\mathrm{X}$-ray signals (no neutron data were available for this particular discharge, but the neutrons also dropped to zero in similar plasmas). For this shot, the frequency of the disruption precursor oscillation, $13 \mathrm{kHz}$, is similar to that in the non-zero delay shot. Also similar is the magnetic fluctuation amplitude, 10 Gauss peak-to-peak, corresponding to $\frac{\vec{B}_{\theta}}{B_{\theta}} \simeq 0.6 \%$. However, unlike the previous example, the mode grew more rapidly, with a growth time of $\mathbf{5 0}$ $\mu$ sec. Also note that the central SXR oscillation amplitude in the zero delay shot is only approximately $30 \%$ of that in the non-zero delay shot. This difference is not caused by differences in the SXR profile peakedness; for the cases discussed, the SXR profiles were very similar.

For all the cases studied, the precursor oscillations as seen on the soft $X$ ray array exhibited a dominant $\mathrm{m}=$ odd (most probably $\mathrm{m}=1$ ) poloidal structure. The signals observed on the magnetic probes always showed a dominant $m=o d d / n=1$ structure in all cases for which the $m / n$ numbers could be determined. The $m=o d d / n=1$ structure was apparent in these cases even when $q_{w} \geq 4$. For the cases in which the m-component could be identified, it was an $m=3$. While some even- $m$ component was also present, the $m=e$ even amplitude was generally less than $50 \%$ of that of the odd component. The precise 
m-number of the even component could not be identified.

\subsubsection{Pre-Distuption Event}

In this section, we will discuss the event following the precursor mode grow th in more detail, and relate the structure of this event to the associated plasma energy loss. Here, we focus on shots with non-zero delays, where the event did not coincide with the disruption and therefore accounted for only a partial energy loss from the plasma. The pre-disruption event occurred simultaneously across the plasma to within the temporal resolution of the SXR data acquisition hardware $(5 \mu \mathrm{sec})$. This indicates the global nature of the modes involved in these low-q discharges, for the subset of non-zero. delay discharges.

Time averages of the chord-integrated horizontal SXR signals before and after the event were taken in order to construct the profile of the change in SXR emissivity through the event. In the absence of time-resolved plasma density and temperature profiles during this time, the SXR profiles thus constructed serve as a guide to the change in plasma energy across the profile. The profiles for three typical events are shown in Fig. 7, and the profiles show $n$ in this figure span the range of profiles observed. $\Delta S /\langle S\rangle$ is defined as $\frac{2\left(S_{2}-S_{1}\right)}{\left(S_{2}+S_{1}\right)}$ where the $S_{1}, S_{2}$ are the time-averaged SXR signals before and after the event, respectively, for each sightline. The time averages were computed for approximately 1 msec of data ( $\geq 50$ data points for these discharges), and the time-averaging period was chosen to exclude both the transient assuciated with the event and any long period, non-zero trend of the SXR signal. The $\triangle S /\langle S\rangle$ values are plotted as a function of vertical position, $Z$, where $Z$ is the vertical position of the point of intersection between the horizontal SXR chord sightline and $\mathrm{R}=145 \mathrm{~cm}$. The upper and lower extents of these bean-shaped plasmas, as shown in Fig. 1 , were at $Z=\$ 50 \mathrm{~cm}$; however, the SXR data beyond $Z= \pm 42 \mathrm{~cm}$ were poor.

As can be seen in the figure, the $\Delta S /\langle S\rangle$ profile varied great!y. For instance, the profile for shot 97447 shows a decrease in the central SXR channel of $6 \%$ and an inversion radius at $Z= \pm 10 \mathrm{~cm}$. Associated with this event was a $9 \%$ drop in $\beta_{\text {pol. }}$. This particular event was one of the mildest, in terms of energy loss, observed. Shot 95822 exhibits an inversion radius farther axay from the plasma center, at $Z= \pm 18 \mathrm{~cm}$, and a much greater drop in the 
central SXR channel, approximately $40 \%$. The relative loss of plasma stored energy was $18 \%$. There is the suggestion of a second inversion near $Z=$ $=35 \mathrm{~cm}$; however, the large data uncertainties in this region prevent anything more than speculation on this point. The SXR structure for shot 95722 exhibits no inversion; that is, the SXR signals decreased across the plasma without exhibiting any region of increased emissivity. For this discharge, the drop in the central SXR signal reached $70 \%$, and the total energy loss was $29 \%$. The SXR signals show a minimum drop near $Z= \pm 25 \mathrm{~cm}$, the same radjus as the maximum $\Delta S /\langle S\rangle$ for the other two cases. The source of this effect is not apparent, although several possibilities exist. One possibility is that the feature at $Z= \pm 25 \mathrm{~cm}$ is due to some localized emissivity, although the recurrence of this feature in discharges with different parameters tend to make this explanation alone unlikely. Another possibility, as mentioned, is that the depression in the profile beyond $Z= \pm 25 \mathrm{~cm}$ signifies a reconnection at another rational surface. (e.g., $q=2$ ). The feature at $Z= \pm 25 \mathrm{crn}$ may therefore be a localized region of relative "good" confinement, setween two reconnection of stochastic regions, giving rise to $\Delta S /\langle S\rangle>0$ (vr, as in the case of shot 95722 , a region in which $\Delta S /\langle S\rangle$ is lass negative). It is tempting to infer from the profile for shot $95722(\Delta S /\langle S\rangle<0$ everywhere) that the entire plasma underwent some process of field line ergodization.

For the low- $q_{\psi}$ discharges studied here, the relationship between the plasma energy loss at each event and the structure of the SXR profile across the event was a generally consistent feature. A subset of eleven events with non-zero delay and with high time resolution SXR data at the time of interest was used, and the results are shown in Figs. $8 \mathrm{a}$ and $\mathrm{b}$. The relative loss of plasma energy across the event is plotted as a function of inversion radius in Fig. 8a and against $\Delta S(0) /\langle S(0)\rangle$ in Fig. 8b. While scatter does exist in the data, especially in Fig. 8a, the general trend is that the relative energy loss appears to increase with both $\Delta S(0) /(S(0))$ and inversion radius. It is also the case that the inversion radius and $\Delta S(0) /\langle S(0)\rangle$ are related, the drop in the central SXR signal increasing with inversion radius, and thus the region of energy reduction, and total energy loss, increases.

A hature of these events, however, is that there is little way to predetermine the structure of the event from discharge or precursor mode characteristics prior to the event. In particular, the structure of the event (e.g., $\triangle S(0) /\langle S(0)\rangle$ or inversion radius) was studied with respect to $\left\langle\beta_{t}\right\rangle,\left\langle\beta_{l}\right\rangle / \beta_{c}$, $q_{\psi}$, and frequency, amplitude, growth rate, and mode structure (ratio of cen- 
tral to edge fluctuation amplitude) of the precursor mode oscillation. No obvious dependence on any of these parameters was observed. This is in agreement with the results fourd in Takahashj et al. [8]. In that study, they concluded that there was no clear precursor activity associated with crashes that resulted in large energy loss.

The events differ from conventional sawteeth in that they always led to some loss of energy from the plasma, and they exhibited inversion radii that were larger than those of sawteth. A discussion of these detajls can be found in Takahashi et al. [8].

\subsubsection{Delay Period}

As was seen in Fig. 5, the delay period, the period of time between the pre-disruption event and the actual disruption, appeared to be quiet in terms of oscillatory MHD activity. This was especially true for the raw Mimov coil signal. Some smal] amplitude oscillations were sometimes observed internally on the SXR signals (see Fig. 5). However, these fluctuations, even when present, were apparently benign and unrelated to the ultimate disruption.

A clear picture of the plasma behavior during the delay peiod is obtained by examining the integrated magnetic probe signals. To zero ${ }^{\text {th }}$ order, the change in $\bar{B}_{\theta}$ yields qualitative information regarding the in/out motion of the plasma, while the change in $\tilde{B}_{r}$ indicates the up/down motion (both of which may be related through helicity). The change in the structure. of the plasma during the delay period was examined in this fashion for a subset of twenty-five discharges. The number of discharges in this subset was determined by both the availability of data and the discharge having a non-zero delay period.

The integrated signals from the toroidal array of $B_{r}$-Joops clearly indicate growth of a stationary mode. In farticular from these loops, the stationary mode appears to have a predominantly $n=1$ toroidal structure. Of interest is that, despite the stationary nature of the growing mode, for at least one case the plasma was still rotating during a portion of the delay period (as measured by CHERS). A generally consistent feature of the growing $n=1 \bar{B}_{r}$ structure is the position of the $\vec{B}$. nuils; that is, the toroidal locations at

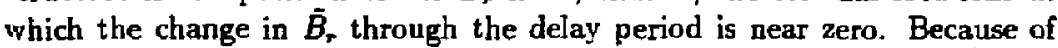
the predominance of the $n=1$ structure, each discharge exhibited two $\tilde{B}_{r}$ null locations. A statistical picture of this observation is shown in Fig. 9. Plotted 
in the figure are the number of occurrences of the $B_{r}$ nuls as a function of torsidal angle. The bimodal distribution reflects the $n=1$ structure, with the $B_{r}$ nulls occurring at toroidal locations of approximately $\phi=120^{\circ}$ and $300^{\circ}$ measured clockwise from North. An examination of the material surfaces and fieid errors was made to determine the cause of the precise positioning of the mode lock. No material feature could readily be identified with either the positions of the $B_{r}$ nulls or extrema. In addition, the toroidal field (TF) ersor was determined to be zero with respect to the TF reference point within measurement uncertainties, ruling this out as a source for the lock position. However, the TF reference point itself was shifted radially outward, with respect to the vessel center, by $\approx 4 \mathrm{~mm}$ at $\phi=120^{\circ}$, thie same toroidal position as the $B_{r}$ nulls. Since the plasma will follow the TF, this shift, and the resulting asymmetry of the poloidal field coils with respect to the $T F$, is the most likely candidate for determining the mode lock position.

The torojdal and poloidal arrays of $B_{\theta}$-loops yield a better piciure of the in/out motion of the plasma, as well as the distortion of the plasma shape

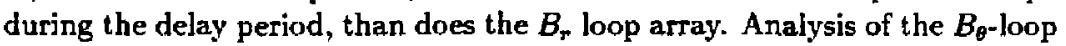
toroidal array indicates also a strong $n=1$ growing perturbation, but it also indicates an $n=0$ perturbation of equal magnitude. The $n=0$ perturbation is in a direction as to reflect an inward shift of the outside and inside boundaries of the plasma at all toroidal locations.

Analysis of the remainder of the poloidal $B_{b}$-loop array indicates severe distortions in the plasma boundary shape during the delay period, as shown in Fig. 10. A schematic of an undistorted plasma is shown; the arrows indicate the relative magnitude and direction of the surface distortion normalized to a $50 \mathrm{G}$ change in $B_{\theta}$ measured at each loop (see scale in figure). As can be seen in the figure, the plasma for this particular shot was pushed in and down, pinched at the midplane, and tilted in the counter-clockwise direction through the course of the delay period. The most comon features of this temporal surface distortion for all the cases studied were the inward shift and mid-plane pinching of the plasma, and the vertical motion, although there were almost as many discharges that moved upwards as that moved downwards. The vertical loss of the plasma following an event in PBX was shown also in Itami et al.[7].

The sequence of salient events leading up to the ultimate plasma disruption in mon-zero delay shots may be understood as follows. The growth of the $n=1$ precursor oscillation leads to a sawtooth-like "crash" which is accom- 
panied by a significant loss of energy from the plasma. This loss of energy results in an inward shift of the plasma, in particular an inward shift of the magnetic axis. The inward shift of the axis for a cylindrical plasma can be estimated from pressure balance[18]. For a $25 \%$ decrease in plasma energy due to the pre-disruption event, the inward shift of the magnetic axis can be expected to be as much as $10 \mathrm{~cm}$ for typical low- $q_{\psi}$ discharge parameters and a magnetic deca! index of $n=-2$ (typical for PBX fields). While this estimate of inward shift is a crude estimate and is valid for, at most, a weakly shaped plasma, the sequence of events was modelled for an actual PBX discharge using the Tokamak Simulation Code (TSC) [19], and good agreement was found between the experimental and computed magnetic signals. In that modelling exercise, a discharge with an extreme energy loss, i.e., one with zero delay, was the basis of the calculation. The inward shift of the axis in turn led to a growth rate of the axisymmetric vertical instability which was on an ideal time scale[19]. On this time scale, the active feedback system on PBX was unable to maintain the vertical position of the plasma.

\subsection{Statistical Analysis of Disruption Parameters}

In this section we will examine the various disruption characteristics statistically in an attempt to understand the features of the mode and plasma that allow the discharge to survive the longest. In addition, the statistical view will allow us to determine better whether the mode responsible for the disruptions at the lowest $q_{\psi}(\leq 3)$ is the same as that at slightly higher $q_{\psi}$ $(\geq 4)$. We can determine this by noting whether the disruption parameters exhibit smooth or discontinuous variations in the range of $q_{\psi}$-values studied. The parameters we will focus on are precursor mode frequency, mode growth times, relative edge to central fluctuation amplitude, and delay times.

In Fig. 11 we show the precursor mode frequency as a function of $q_{w}$. The mode frequencies ranged from 0 to $25 \mathrm{kHz}$, and, while a great deal of scatter does exist, generally increased with $q_{\psi}$, ranging from $\leq 12 \mathrm{kHz}$ for $q_{v} \leq 3$ to values in excess of $20 \mathrm{kHz}$ at the highest $q_{w}$. As is seen in the plot, two discharges exhibited a growing zero frequency mode; these were shots with zero delay, and the zero frequency growth is interpreted as a growing locked mode, as was the case for the mode growth during the delay period. The mode frequency was found not to be a function of either $\left(\beta_{t}\right)$ or $\left\langle\beta_{t}\right) / \beta_{c}$.

The ratio of the mode frequency to plasma rotation frequency, $f_{M} / f_{R}$, 
is plotted in Fig. 12 as a function of $q_{\psi}$. For most of the points plotted, the plasma rotation frequency was taken at the plasma center. In about $20 \%$ of these shots, central totation velocities were not measured, and offaxis values were taken. However, values were always taken within $7 \mathrm{~cm}$ of the axis $(r / a \simeq 0.20)$. The first feature to note from the figure is that the range of $f_{M} / f_{R}$ values went from zero to $\geq 1.5$ and exhibited a great deal of variability within limited $q_{\psi}$ ranges. This indicates that the precursor mode was decoupled from the central plasma rotation. $A$ coupling hetween the two would lead to constant $f_{M} / f_{R}$ for all $q_{\psi}$, or at least far less variability in the range of values for each $q_{\psi}$ range. This decoupling of mode and rotation frequency is consistent with the observation that the plasma could be rotating even during the delay (mode lock) period.

The second feature to note from the figure is that, while there is again a great deal of scatter in the data, the mode frequency in general increased relative to the rotation frequency as $q_{\psi}$ increased. The reason for this is that while $f_{R}$ exhibited no functional dependence on $q_{\psi}$, the mode frequency increased with $q_{\psi}$, as was seen in Fig. 11. It is clear from these figures that the plasma characteristics controlling the mode frequency are not simply determined. The mode frequency was most likely determined by eithes some global, profile dependent average of some parameter (not likely to be rotation frequency since $f_{M} / f_{R} \geq 1$ at the higher $q_{\psi}$ ), or by some local internal characteristic whose position is q-dependent.

The growth time of the disruption precursor mode, $\tau_{G}$, is plotted in Fig. 13 as a function of $q_{\psi}$. Here, $q_{\psi}$ is the value taken just prior to the disruption or pre-disruption event, and the growth time is defined as before. While there is no apparent trend between growth times and $g_{w}$, what emerges from the figure is the range and variability of $\tau_{G}$ for all, and at each, $q_{\psi}$. The growth times range from $20 \mu s e c$ to 2 msec. As was discussed in a previous paper $\{5]$, these growth time values span the range between those expected from ideal and resistive MHD time scales. As was also pointed out in the previous paper, growth times of order $100 \mu \mathrm{sec}$ can be accounted for within the framework of ideal MHD theory by taking into account the evolution of the discharge equilibrium through the marginal state for instability. Nevertheless. the majority of discharges do exhibit growth times in excess of 100 $\mu$ sec, and therefore cannot be readily explained on the basis of ideal MHD theory alone.

While there was no apparent dependence of mode frequency on plasma 
rotation, this was not the case for the mode growth time. Figure 14 shows the growth time as a function of central (or near central) rotation velocity. The figure indicates a relationship (albeit weak) between $v_{\varphi}$ and $\tau_{G}$, with the shorter growth times (faster mode growth) associated with the faster rotating plasmas. There is some variability in jnjected power for the shots shown in the graph $\left(P_{i n j} \simeq 2.5-5 \mathrm{MF}\right)^{-}$, however, neither the growth times nor rotation velocities show any clear statistical trend with beam power that could account for the dependence shown in Fig. 14. The dependence of $\tau_{G}$ on $v_{\varphi}$ is retained even if the data are constrained to a narrower range of beam powers. Additionally, any dependence of growth times or rotation velocities on the relative amount of parallel to perpendicular injection power was ruled out. For the set of discharges studjed, the ratio of parallel to total injected power was limited to between 30 and $50 \%$, and no dependence was observed within this restricted range. The dependence shown in Fig. 14 may indicate a relationship between the plasma viscosity or momentum diffusivity that can slow the plasma rotation, and the nonideal effects such as resistivity that can slow the mode growth rate[20].

In order to study the coupling between the edge and internal oscillations, the relative strength of the edge to central fluctuation amplitudes was studied using the Mirnov coil signal and a near central soft $X$-ray signal. The relative edge fluctuation amplitude is defined as $\bar{B}_{\theta} / B_{\theta}$, where $\bar{B}_{\theta}$ is the absolute amplitude of the magnetic fluctuation at a midplane Mirnov coil situated approximately $30 \mathrm{~cm}$ outside the plasma. $B_{\theta}$ is the poloidal field at the coil due to the plasma current. The relative near-central signal is defined as $\bar{S} /\langle S\rangle$, where $\bar{S}$ is the amplitude of the oscillating portion of the soft X-ray emissivity, and $\langle S\rangle$ is the average emissivity for the time period of interest. We define the relative edge to central fiuctuation amplitude to be $\frac{\vec{B}_{\theta} / B_{\theta}}{\tilde{S} /\langle S\rangle}$. The dependence of this quantity on $\left\langle\beta_{t}\right\rangle$ and $\left\langle\beta_{t}\right\rangle / \beta_{c}$ is shown in Figs. $15 a$ and $15 \mathrm{~b}$. The importance of the edge fluctuation relative to the central fluctuation is a function of either the absolute or normalized $\beta$, increasing by almost a factor of five across the range of $\left\langle\beta_{t}\right\rangle$. Most of this dependence is due to the increase of $\bar{B}_{\theta} / B_{\theta}$ with the relevant parameter; little change is seen in $\bar{S} /\langle S\rangle$ as a function of $\left\langle\beta_{l}\right\rangle$ or $\left\langle\beta_{t}\right\rangle / \beta_{c}$. It is also of interest that the faster growing modes are associated with the higher relative edge to central fluctuation amplitudes, as is seen in Fig. 16. It therefore appears that it is the discharges with the greatest relative level of edge fluctuations that 
behave the most ideally in terms of the time scales for mode growth, and these discharges occur at the highest $\left\langle\beta_{\ell}\right\rangle$.

While the relative edge to central fluctuatica amplitude, and edge amplitude alone, are $\mathfrak{t}$ unctions of $\beta$, there is no dependence of these quantities on $q_{\psi}$. However, what does appear to depend on $q_{\psi}$ is the relative central fluctuation amplitude. This is seen in Fig. 17 a where $\bar{S} /\langle S\rangle$ is plotted as a function of $q_{\psi}$. Here no attempt was made to sort the data into zero or non-zero delay shots, but as will be seen the longer delay shots generally occurred at the higher $-q_{\psi}$. Figure $17 \mathrm{a}$ indicates that the lower internal fluctuation amplitudes occurred in discharges that have survived to lower- $q_{\psi}$. Therefore, suppression or reduction of the internal oscillation amplitude through current profile modification may be one route towards attaining low $q_{\psi}$. On the other hand, the causal relation may be reversed; plasma conditions or profile shapes that allowed the discharge to survive to lower- $q_{w}$ are ones that may have naturally led to lower internal Auctuation amplitudes. Possible effects to this end include the precise value of $q(0)$, the location of the $q=1$ surface, or the $q$-profile at $q=i$. At present, there are no measurements of the q-profile or $q(0)$, and there is no way to determine unambiguously the causal relationship between the strength of the internal $m=1 / n=1$ oscillation and discharge surviva'

One indication of how the internal fluctus ions depend on current profile shape is the dependence on $L_{i} / 2$, where $L_{i} / 2$ was computed from a between shots equilibrium code using the diamagnetic loop signal and flux loop signals as input. The value of $l_{i} / 2$ is determined from the computed $\Lambda$ and measured $\beta_{\text {pot }}$ as determined from the diamagnetic loop signal. In about $30 \%$ of the cases used, the latter measurement was not avajlable, and $l_{i} / 2$ was determined from an empirical expression relating this parameter to $q_{w}$. The values of $i_{i} / 2$ determined in this fashion agreed well with those computed using the measured $\beta_{\mathrm{pod}}$, for the same discharge, when the values were compared. As seen in Fig. 17b, the near-central internal fluctuation amplitude increases with increasing $l_{i} / 2$ (more peaked current profile). As can also be soen, there is little difference in this dependence for discharges with zero or non-zero delay. There is a group of four points at high $t_{i} / 2(>0.30)$ exhibiting small relative fluctuation amplitudes $(\leq 0.15)$. Statistically, there is no difference between this group of discharges and those at the high or low $\left[\bar{S} /\langle S\rangle, l_{i} / 2\right]$ end. That is, the SXR profiles for this group of points exhibit the same range of peakedness (which affects $\hat{S}$ directly) as those at the other extremes. The 
only difference found was in the value of $\left\langle\beta_{t}\right\rangle / \beta_{\mathrm{c}}$. For those four discharges, $\left\langle\beta_{t}\right) / \beta_{c}=1.7$ to 1.8 , while for the discharges at the other extremes, $\left\langle\beta_{t}\right\rangle / \beta_{c} \simeq$ 1.3 to 1.6. Nevertheless, the overall trend in the figure does suggest that broader discharges, with lower shear in the central region, exhibit smaller relative intemal fluctuation amplitudes. However, this dependence does not influence whether the discharge will disrupt immediately after the event or with some finite delay.

Finally, we turn to the statistical characteristics of the delay period. Plotted in Fig. 18a is the delay time, $\tau_{D}$, as a function of $g_{\psi}$. The first feature to note from Fig. 18a is that not only do zero delay shots essentially extend through the entire range of $q_{\psi}$ studied, but there are even low- $q_{\psi}\left(q_{\psi}<3\right)$ that have non-zero delays. The second feature is that, in general, the average delay time for each narrow range of $q_{\psi}$ increases as a function of $q_{\psi}$. The horizontal bars represent straight averages of the delay times in each $\Delta q_{v}=0.5$ bin. The average delay time increases from zero in the lowest bin $t_{0} \approx 9 \mathrm{msec}$ in the highest $g_{\psi}$ range. It is also seen that the envelope value of $T_{D}$ also increases with increasing $q_{\psi}$. What may also be a significant feature of Fig. 18a is the behavior of discharges 't integer $q_{\psi}$ values, where "spikes" in the distribution of delay times appear. While this may be a real feature, the possibility that this is a spurious observation due to limited data cannot be ruled out.

An additional dependence appears to be between the delay time and $\left\langle\beta_{t}\right\rangle$. This is shown in Fig. 18b. At the lowes $\left\langle\beta_{t}\right\rangle$ values, the delay times can be greatest, and few shots have zero delays. On the other hand, above $\left\langle\beta_{t}\right\rangle=3.7 \%$, all shots have zero delay times. These high- $\left\langle\beta_{t}\right\rangle$ shots are the ones with the greatest relative edge to central fluctuation amplitudes.

In Fig. 14 it was shown that the fastest rotating plasmas behaved in a manner most consistent with ideal MHD theory with respect to the precursor mude growth time, the fastest growth rates being associated with the fastest rotating plasmas. In Fig. 19 we show a complimentary result, where the delay time is plotted as a function of rotation velocity. The highest rotation velocity plasmas are clearly associated with discharges that only have zero delay. If, as mentioned in the previous section, we take the change in the soft X-ray profiles across the pre-disruption event for non-zero delay shots as indicative of some resistive process, then it is the slowly rotating plasmas that appear to be the most resistive (e.g., slowest growth rates and non-zero delays). 


\section{Conclusions}

\subsection{Summary}

To summarize, low- $q_{\psi}$ operation in PBX has indicated that disruptions always occur for discharges with $q_{\psi} \leq 3.3$. This result is independent of the proximity to the theoretical $\beta$-limit for these low- $q_{\phi}$ values, although the precise character of the disruption can vary greatly. A caveat is that the inevitability of disruption may be unique to the transient nature of $\mathrm{PBX}$ low- $q_{\psi}$ operation; the PBX plasmas were highly elongated and low- $q_{\psi}$ was obtained by strongly ramping the plasma current $\left(\dot{I}_{p} \geq 1.5 \mathrm{M} / \mathrm{A} / \mathrm{sec}\right)$. Nondisruotive discharges at $g_{\psi} \simeq 2.5$ were routinely attained in PDX diverted discharges; however, the elongation of these diverted discharges was $\approx 1.0$.

The disruptions in PBX were preceded by the growth of a precursor mode oscillation, and the culminating crash of this mode led to a disruption either immediately or with in several msec delay. In the latter case, the crash, or pre-disruption event, is the $\beta$-limiting process, and it is associated with only a partial energy loss from the plasma with no current disruption. Additionally, in these non-zero delay shots, the change in the soft X-ray emissivity profile across the event may indicate the occurrence of some resistive process, either localized reconnection or more widespread field line ergodization. The period between the event and the actual disruption is one of stationary mode growth and one where the plasma, due to an inward shift of the magnetic axis as a result of the energy loss, becomes vertically unstable and is lost.

The details of the disruption precursor mode exhibit a large range of variability. The mode frequency varies from a few to $\simeq 20 \mathrm{kHz}$ on a shot to shot basis, but shows no apparent coupling to the plasma rotation frequency. Growth times of the mode vary from $\simeq 10 \mu \mathrm{sec}$ to a few msec, and the fastest growing modes, and discharges with shortest delay times, are more often seen in plasmas with the largest rotation velocities. The delay times show additional dependences, derreasing with decreasing $q_{\psi}$ or increasing $\left\langle\beta_{\mathrm{t}}\right\rangle$. The lat ter dependence implies that disruptions are almost al ways immediate near the $\left\langle\beta_{t}\right\rangle$-limit. The relative edge to central fluctuation amplitude increases with increasing $\left\langle\beta_{t}\right\rangle$, due mostly to the increase in edge fluctuation amplitude with $\left\langle\beta_{c}\right\rangle$. The central fluctuation amplitude generally decreases with decreasing $q_{\psi}$ and broader current profile (lower $l_{i} / 2$ ).

The data strongly suggest that over the range of $q_{\psi}$ studjed $(\simeq 2.5$ to 
4.5), the disruptions are caused by different manifestations of the same global mode. This conclusion is based primarily on the continuum of disruption characteristics and the continuous change of these characteristics with changes in the various discharge parameters. Different global modes would most likely have sharply contrasting characterizations in the different ranges of $q_{\psi}$ studied. The data suggest a transition from a more ideal MHD-like condition to a more resistive one as $q_{\psi}$ increases and $\left\langle\beta_{\ell}\right\rangle$ decreases.

Also apparent from the data is that the parameters, or variation in parameters, that are important for attaining low- $q_{\psi}$ and high- $\left\langle\beta_{\ell}\right\rangle$ are not necessarily the same and do not necessarily interdepend on each other even though the highest- $\left\langle\beta_{t}\right\rangle$ discharges generally occur at the lowest- $q_{w}$. An example of this is given by the mode growth time and the relative edge to central fluctuation amplitude. The higher- $\left\langle\beta_{t}\right\rangle$ discharges are those that are associated with the higher levels of edge to central fluctuations, and the higher edge to central fluctuation amplitude discharges are associated with the shorier growth times. However, there is no clear statistical dependence of mode growth time on $\left\langle\beta_{l}\right\rangle$ directly. The lack of this interdependence may simply be due to the linited working data set.

\subsection{Discussion}

While the observed dependence of the internal fluctuation level on $q_{\psi}$ and $l_{i} / 2$ may well be a crucial indicator for low- $q_{\psi}$ operation, the causality of this dependence is uncertain. Whether the lower internal fluctuation amf litudes allowed the di: charge to survive to lower $q_{\psi}$, or whether the discharge parameters or profiles that enabled the discharge to survive to lower $g_{\psi}$ suppressed the internal fluctuations merely as a by-product, is not known. Even in the first case, where the internal fluctuation amplitude would have a dirert bearing on the discharge survival, the way to proceed for future low- $q_{w}$ operation is unclear. The reason for this uncertainty is the physical source and, therefore, the potential means of suppressing the internal ascillations. One possible source of these oscillations is the current driven $n=1$ internal kink mode. For this to be the case, $q(0)<1$, and the mode will generally be localized to inside the $q=1$ surface. If internal kinks are the source of these internal modes, they can be effectively stabilized in the presence of indented flux surfaces near the $q=1$ rational surface[21]. As was seen for the high- $\left\langle\beta_{\epsilon}\right\rangle$ equilibrium shown in Fig. 1, very little indentation could be produced near 
the $q=1$ surface.

An alternative source of the internal oscillations are pressure-driven "infernal modes" [22]. These modes can exist for $q(0)>1$ and can even have an $\mathrm{m}=1 / \mathrm{n}=1$ contribution in the absence of a $\mathrm{q}=1$ surface[22]. Whether internal kinks or infernal modes dominate depends critically on the details of both the current and pressure profiles, details that are beyond the capabilities of the diagnostic set on PBX. Knowing how the infernal modes behave with plasma shaping alone is difficult because of pressure profile effects. For fixed pressure profile, flux surface shaping (indentation) that leads to lower shear will actually have a destabilizing effect on these infernal modes, although stabilization can be effected if the pressure profile is broadened so that the pressure gradient is shifted to lie outside the low shear region.

The data, unfortunately, cannot distinguish between the two possible modes (current driven internal kinks or pressure driven infernal modes). No $q(0)$ measurement exists; therefore this method of identification is not available. We do note, however, that the lowest- $q_{\psi}$ discharges do not exhibit the internal kink driven "fishbone" oscillations near the time of the disruption. On the other hand, the lower internal fluctuation amplitude with broader current profile (lower shear) may at first seem incompatible with the hypothesis that the internal fluctuations are due to infernal modes since these modes are more unstable in the presence of low central shear. However, since we do not know the details of the pressure profiles for these shots, we are again unable to conclude anything regarding the source of these internal fluctuations.

Earlier discussions of these low- $q_{\psi}$ disruptions identify the ideal external kink to be the cause. These conclusions were based primarily on global stability calculations $[4]$, and sume comparisons between the details of the observed and theoretically expected MHD activity for this mode[5]. Nevertheless, it was recognized in Jahns et al.[5] that the nonideal effects were important. Key conclusions from this present study are that the mode responsible for the disruption and/or $\left\langle\beta_{\mathrm{t}}\right\rangle$-limit is neither purely external nor purely ideal. That the mode is not purely external is obvious from the presence and importance of the internal fluctuations. While the free energy for the oscillation leading to the disruption may come from the edge, the oscillations are clearly coupled to the plasma interior. Such coupling is achievable even within the framework of ideal MHD theory. It is of interest to point out, in light of the discussion in the previous paragraph, that the internal eigenmodes calculated for a high- $\left\langle\beta_{t}\right\rangle$ equilibrium were dominated by the pressure-driven 
terms [5!. Additionally, as seen in Fig. 7, the energy loss associated with the $\left\langle\beta_{t}\right\rangle$-limiting pre-disruption event can be localized not at the edge of the plasma, but rather in the center (shots 97447,95822 ).

The other key conclusion from this study is that the mode is not purely ideal. The first piece of evidence for this assertion is the growth time of the mode leading to the disruption or pre-disruption event. While growth times in the 10 's or even $\approx 100$ 's of $\mu$ sec can be accounted for within the framework of ideal theory $[5,23]$, the largest number of discharges studied here have growth times in excess of hundreds of $\mu \mathrm{sec}$, up to several msec. A conducting wall has a stabilizing effect on ideal modes, and is one way of slowing growth times by an order of magnitude.

A nother effect which would slow the mode growth rates is the existence of some finite plasma resistivity. The $m=2 / n=1$ tearing mode has historically been thought of as one fundamental cause of plasma disruptions[24-29]. The disruption is believed to occur when the $2 / 1$ island overlaps with a $3 / 2$ island, or contacts the limiter directiy. The $2 / 1$ tearing mode has recently beer invoked to explain high- $\left\langle\beta_{t}\right\rangle$ disruptions on the DIII tokamak[30]. While there is no clear evidence from either the soft $X$-ray or Mirnov coil array that $2 / 1$ islands exist within the PBX plasmas at these low- $q_{\psi}$, we do note the existence of at least some $m=e v e n / n=1$ component from the Mirnov coil signals for the discharges studied. However, in practically all cases, the $m=3$ component amplitude is greater than that of the even-m component by at least a factor of two. In addition, it was not possible to determine whether the even-m component was $m=2$. We do not rule out the possibility of $3 / 1$ tearing islands being responsible for the observed oscillations.

The existence of shots with pre-disruption events that lead to energy loss but not current loss is also evjdence for the resistive character of the modes, or more specifically the resistive character of the mode "crashes." The structure of the SXK profile change across the time of the event can reflect an energy luss in the central portion of the plasma, but an increased emissivity farther oul. This energy transfer at constant $I_{p}$ may be explained by magnetic reconfiguration of the internal portion of the plasma brought about by resistive reconnection near the $q=1$ surface and perhaps an additional reconnection region at higher rational $q_{\psi}$ surfaces. Alternatively, the large regions of $د S(0) /\langle S(0)\rangle<0$, in some cases extending over the entire plasma, suggests more extensive stochastic behavior of the field lines. Stochasticity in the growth of an $m=1$ tearing island has been invoked to explain the char- 
acter of internal distuptions in TFR $[31,32]$ and large energy loss sawteeth in $\mathrm{FBX}[8]$. On the other hand, it is believed that the growth of an ideal $m=1$ mode is responsible for the rapid sawtooth collapses in JET[33,34]. The importance of nonideal effects (e.g., a resistive plasma mantle) for PBX plasmas was shown quantitatively in Jahns et al.[5].

How the resistive nature of the plarma may affect future tokamak operation (e.g., CIT) is unknown. The PBX device is being modified based on theoretical grounds that close fitting conducting walls will stabilize the $n=1$ ideal external kink. The objective of PBX-M, the modified PBX, is to explore the second stability regime to ballooning. To do this, the disruptive limit of the external kink must be overcome, and stabilization of this ideal mode will be attempted with the close fitting walls. However, the passive stabilization properties of the conducting walls may be oftset by the longer time scales characteristic of the resistive regime and, in particular, of discharges exhibiting stationary mode growth. The PBX-M device will be able to address this crucial issue.

\section{Acknowledgments}

The authors gratefully acknowledge discussions with K. McGuire and D. Buchenauer. The PBX project was supported by the U. S. Dept. of Energy Contract No. DE-AC02-76-CHO-3073. 


\section{References}

11. TROYON, F., GRURER, R., SAUREMANN, H., SEMENZATO, S., and SUCCI, S., Plasma Physics and Controlled Fusion 26 (1984) 209.

[2] SYKES, A., TURNER, M., and PATEL, S., in Controlled Fusion and Plasma Physics, Vol. 2 (Proc. 11th Europ. Conf. on Controlled Fusion and Plasma Physics, Aachen, 1983, Europhys. Conf. Abstracts, 1983) p. 363.

[3] TROYON, F, ana GRUBER, R., Phys. Lett. A 110 (1985) 29.

[4] BOL, K., BUCHENAUER, D., CHANCE, MI., COUTURE, P., FISHMAN, 1 ., and ET AL., Phys. Rev. Lett. 57 (1986) 1891.

[5] JAHNS, G., CHANCE, M., KAYE, S., MANICKAM, J., TAKAHASHI, H., and ET AL., Princeton Plasma Physics Laboratory Report PPPL$2482,1987$.

6; GRIMM, R., GREENE, J., and JOHNSON, J., Meth. Comp. Physics $16(1976) 253$.

77. ITAMI, K., JAHNS, G., YAMADA, H., and MCGUIRE, K., Frinceton Plasma Physics Laboratory Report PPPL-2260, 1985.

I8 TAKAHASHI, H., MORRIS, W., SESNIC, S., BOL, K., FONCK, R., and ET AL., Princeton Plasma Physics Laboratory Report PPPL-2391, 1986.

[9] OKABAYASHI, M., BOL, K., CHANCE, M., COUTURE, P., FISHMAN, H., and ET AL., in Plasma Phys. Cont. Nuclear Fusion Research, Vol. 1 (Proc. 11th Int. Conf. Kyoto, 1986, IAEA, Vienna, Austria, 1987) p. 275.

(10) GRIMM, R., CHANCE, M., TODD, A., MANICKAM, J., OKABAYASHI, M., and ET AL., Nucl. Fusion 25 (1985) 805.

(11) MCGUIRE, K., BELL, M., BITTER, M., BOL, K, BRAU, K., and ET AL., Phys. Rev. Lett. 50 (1983) 891. 
12] STRACHAN, J., GREK, B., HEIDBRINK, W., JOHNSON, D., KAYE, S., and ET AL., Nucl. Fusion 25 (1985) 863.

13] HEIDBRINK, W., KAITA, R., TAKAHASHI, H., GAMMEL, G., HAMMETT, G., and KAYE, S., Phys. Fluids 30 (1987) 1839.

[14] FONCK, R., GOLDSTON, R., KAITA, R., and POST, D., Appl. Phys. Lett. 42 (1983) 239.

[15] JOHNSON, D., BELL, M., BITTER, M., BOL, K., BRAU, K., and ET AL., in Plasma Phys. Cont. Nuclear Fusion Research, Vol. 1 (Proc. 9th Int. Conf. Baltimore, 1982, IAEA, Vienna, Austria, 1983) p. 9.

[16] STAMBAUgh, R., MOORE, R., BERNARD, L., KELLMAN, A., STRAIT, E., and ET AL., in Plasma Phys. Cont. Nuclear Fusion Research, Vol. 1 (Proc. 10th Int. Conf. London, 1984, IAEA, Vienna, Austria, 1985) p. 217.

[17] GRUBER, O., BECKER, G., V.GIERKE, G., GRASSIE, K., KLLBER, O., and ET AL., in Plasma Phys. Cont. Nuclear Fusion Research, Vol. 1 (Proc. 11th Int. Conf. Kyoto, 1986, Vienna, Austria. 1987) p. 357.

[18] OKABAYASHI, M., MAEDA, H., TAKAHASHI, H., and REUSCH, M., Nucl. Fusion 21 (1981) 271.

(19) JARDIN, S., DELUCIA, J., OKABAYASHI, M., POMPHREY, N., REUSCH, M., , KAYE, S., and TAKAHASHI, H., Nucl. Fusion 27 (1987) 569.

[20] PORCELli, F., Phys. Fluids 30 (1987) 1734.

21) MANICKAM, J.. Nucl. Fusion 24 (1984) 595.

22) MANICKAM, J., POMPHREY, N., and TODD, A., Nucl. Fusion 27 (1987) 1461.

[23] WESSON, J., Nucl. Fusion 18 (1978) 87.

[24] WHITE, R., MONTICELLO, D., and M.N.ROSENBLUTH, Phys. Rev. Lett. 39 (1977) 1618. 
[25] CARRERAS, B., HICKS, H., HOLMES, J., and WADDELL, B., in Proceedings of the IAEA Symposium on Current Disruption in Toroidal Devices (Max-Planck-Institut fur Plasmaphysik. 1979) [Paper A1].

[26] BISKAMP, D. and WELTER, H., in Proceedings of the IAEA Symposium on Current Disruption in Toroidal Devices (Max-Planck-Institut fur Plasmaphysik, 1979) [Paper A2].

[27] ROBINSON, D. and MCGUIRE, K., in Proceedings of the IAEA Symposium on Current Disruption in Toroidal Devices (Max-Planck-Institut fur Plasmaphysik, 1979) [Paper D9].

[28] WhITE, R. and MONTICELLO, D., Princeton Plasma Physics Laboratory Report PPPL-1674, 1980.

[29] TURNER, M. and WESSON, J., Nucl. Fusion 22 (1982) 1069.

[30! CHU, M., STRAIT, E., LEE, J., LAO, L., STAMBAUGH, R., and ET AL., in Plasma Phys. Cont. Nuclear Fusion Research, Vol. 1 (Proc. 11 th Int. Conf. Kyoto, 1986, IAEA, Vienna, Austria, 1987) p. 373.

[31] DUBOIS, M., PECQUET, A., and REVERDIN, C., Nucl. Fusion 23 (1983) 147.

¡32! IZZO, R., MONTICELLO, D., STODIEK, W., and PARK, W., Princeton Plasma Physics Laboratory Report PPPL-2342, 1986.

[33] EDWARDS, A., CAMPBELL, D., ENGELHARDT, W., FAHRBACH, H., GILL, R., and ET AL., Phys. Rev. Lett. 57 (1986) 210.

[34] WESSON, J., Plasma Phys. Cont. Fusion 28 (1986) 243. 


\section{Figures}

Fig. 1. Equilibrium flux contours for a high- $\left\langle\beta_{t}\right\rangle(5.3 \%)$ equilibrium. Discharge characteristics for this shot were $\left\langle\beta_{k}\right\rangle=5.3 \%$. $I_{p}=570 \mathrm{kA}, B_{\mathrm{t}}=$ $0.9 \mathrm{~T}, \bar{n}_{\mathrm{e}} \geq 5 \times 10^{13} \mathrm{~cm}^{-3}, q_{\psi}=3.0, \dot{J}_{\mathrm{p}}=2 \mathrm{MA} / \mathrm{sec}$, and $P_{i n j}=4.7 \mathrm{MW}$ of deuterium beams $(\simeq 45 \mathrm{kel})$ into a hydrogen plasma.

Fig. 2. $\left(\beta_{t}\right)$ as a function of $\mu_{0} I_{p} / a B_{t}$ for PBX discharges with indentations greater than $5 \%$. The discharges are sorted according to whether they were disruptive or non-disruptive. The discharge is defined to be disruptive if it disrupted during or within 10 msec of the period of maximum beam power for that discharge.

Fig. 3. Subset of PBX discharges indicating the total number of shots sorted in bins of $\Delta q_{\psi}=0.2$, and number of disruptive shots (shaded portion of the histogram) for each $\Delta q_{\psi}$ bin.

Fig. 4. Comparison of discharge evolution during the neutral beam heating phase for two discharges, one with $q_{\psi} \simeq 4.5$ (left panel), and one with $g_{\psi} \simeq 2.4$ (right panel) prior to the discharge disruptions. Plotted in each panel is the evolution of $q_{\psi}$ (top), raw Mirnov coil signal (middle), and near-central chord-integrated soft $\mathrm{X}$-ray emissivity (bottom).

Fig. 5. Expanded view of the discharge evolution leading up to the disruption for a discharge with a non-zero delay. Plotted from the top are displaced toroidal flux as measured by the diamagnetic loop, neutron flux, integrated and raw Mirnov coil signal, and central chord-integrated soft $\mathrm{X}$-ray emissivity.

Fig. 6. Same as Fig. 5 for a shot with zero delay. No neutron flux measurements were available for this shot.

Fig. 7. The change in the chord-integrated soft $\mathrm{X}$-ray emissivity due to the pre-disruption event for three nearly identical discharges $\left(g_{\psi} \simeq 3.5-3.9\right)$. The quantity $\frac{\Delta S}{\langle S\rangle}$ is defined as $\frac{2\left(S_{2}-S_{1}\right)}{\left(S_{2}+S_{1}\right)}$ where the $S_{1}, S_{2}$ are the timeaveraged SXR signals before and after the event, respectively, for each sightline. The quantity $\frac{\partial S}{\langle S\rangle}$ is plotted as a function of vertical position 
$\mathrm{Z}$, where $\mathrm{Z}$ is the intersection between the line of sight of the soft $\mathrm{X}$-ray chord and $\mathrm{R}=145 \mathrm{~cm}$.

Fig. 8. (a) Relative change in $\beta_{\text {pol }}$ associated with the pre-disruption event as a function of the inversion radius of the event for discharges with nonzero delays. (b) Same as $8 \mathrm{a}$, but plotted as a function of relative change in the central chord integrated soft X-ray emissivity.

Fig. 9. Histogram indicating the number of times the $\delta B_{\mathrm{r}}$ nulls during the delay period were situated at various toroidal locations. The bimodal nature of the distribution indicates an $n=1$ toroidal mode structure.

Fig. 10. A schematic illustration indicating the direction and qualitative magnitude of the PBX plasma surface perturbation as inferred from the change in $B_{\theta}$ at each coil during the delay period. The length of each arrow is normalized to a $50 \mathrm{G}$ change in $B_{\theta}$ (see scale in the figure). Arrows pointing away from the coils indicate a decrease in $B_{\theta}$ at the coil and therefore a corresponding motion of the plasma surface away from the coil. Arrows pointing towards the coils indicate an increase in $B_{\theta}$ there and motion towards the coil.

Fig. 11. Precursor mode frequency, $f_{m}$, plotted as a function of $q_{i}$. Zero and non-zero delay shots are included.

Fig. 12. Ratio of precursor mode frequency to plasma rotation frequency plutted as a function of $q_{\psi}$. The central plasma rotation frequency was used for most cases, and the rotation frequency within $r / a=0.20$ was used for the remainder.

Fig. 13. Growth time of precursor mode as a function of $q_{\psi}$.

Fig. 14. Growth time of precursor mode as a function of plasma rotation velocity. The rotation velocity values were all measured inside $r / a=0.20$.

Fig. 15. (a) Relative edge to central fluctuation amplitude as a function of $\left(\beta_{t}\right\rangle$. (b) Same as (a), but plotted us $\left\langle\beta_{t}\right\rangle / \beta_{\mathrm{c}}$ where $\mathcal{\beta}_{\mathrm{c}}=\mu_{0} I_{\mathrm{p}} / a B_{t}$.

Fig. 16. Precursor mode growth time plotted as a function of relative edge to central fluctuation amplitude. 
Fig. 17. (a) Normalized fiuctuation amplitude as determined from a near central soft X-ray emissivity signal plotted as a function of $q_{\psi}$. (b) Normalized near-central soft $\mathrm{X}$-ray fluctuation amplitude plotted as a function of $t_{i} / 2$.

Fig. 18. (a) Delay time plotted as a function of $q_{w}$. The horizontal line in each $\Delta q_{\psi}=0.5$ bin is a straight average of the delay times in that bin. (b) Delay time plotted as a function of $\left\langle\beta_{t}\right\rangle$.

Fig. 19. Delay time plotted as a function of plasma rotation velocity. The rotation velocity values were all measured inside of $r / a=0.20$. 


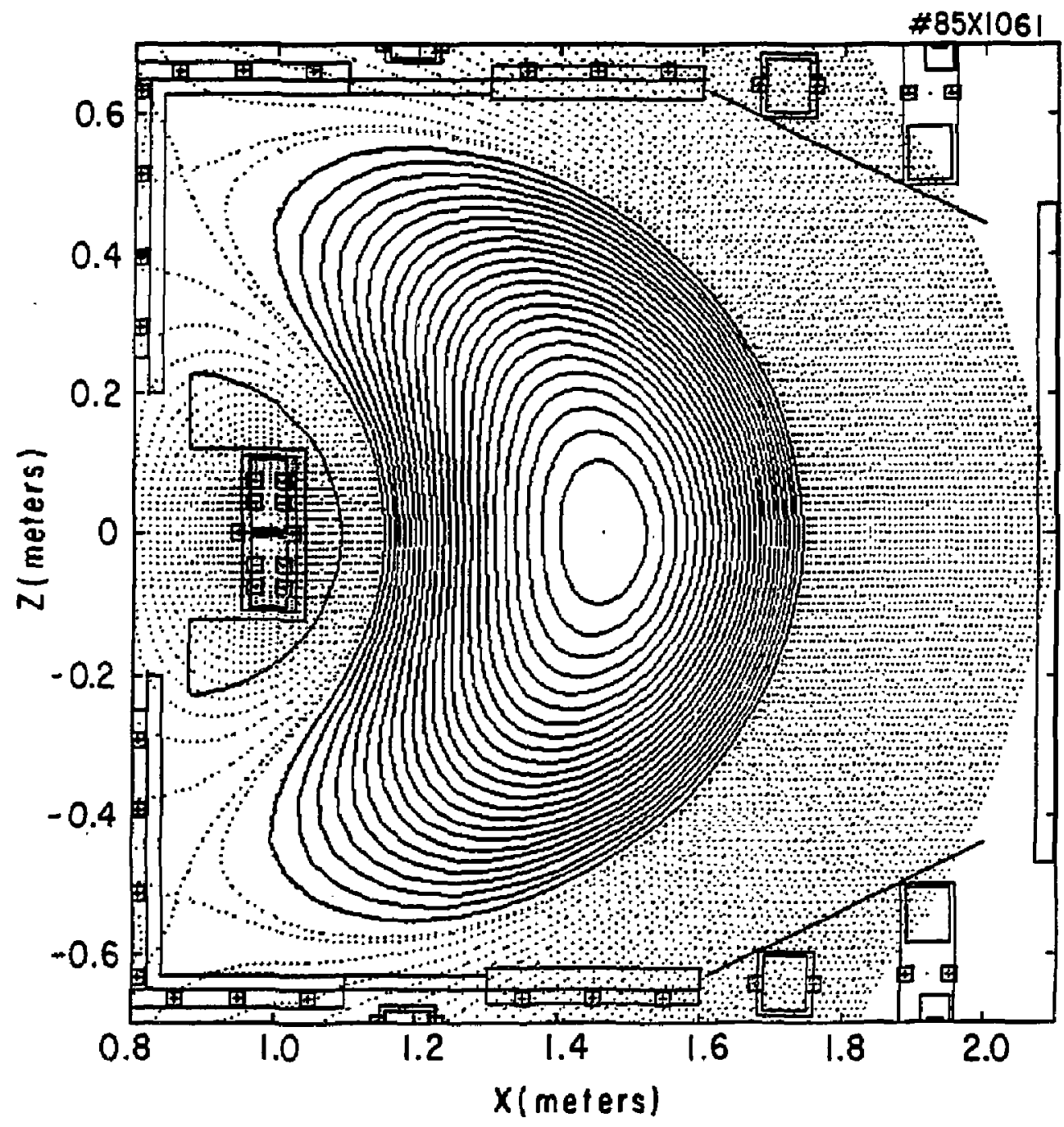

F1gure 1 
\# 87x0912

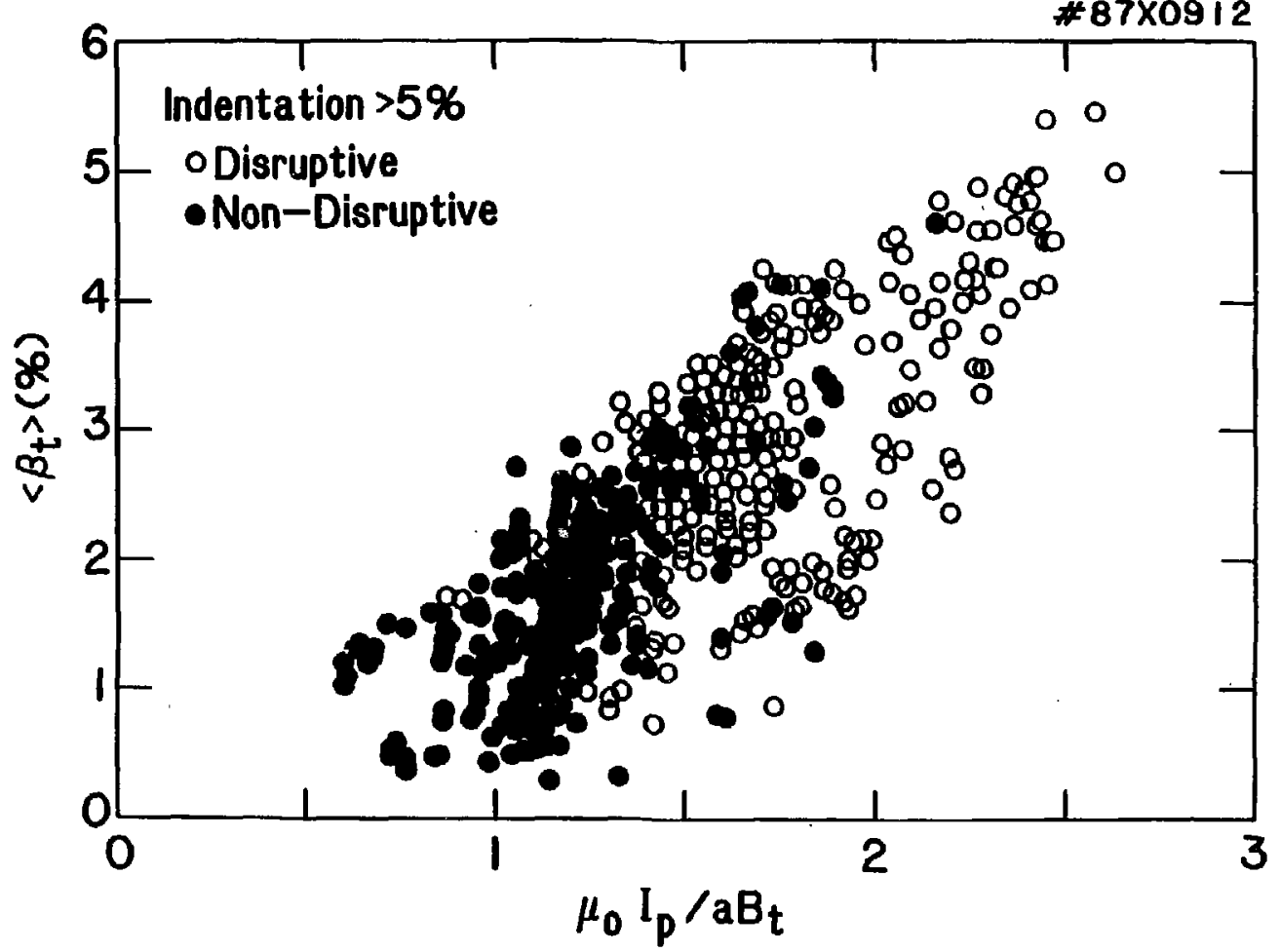




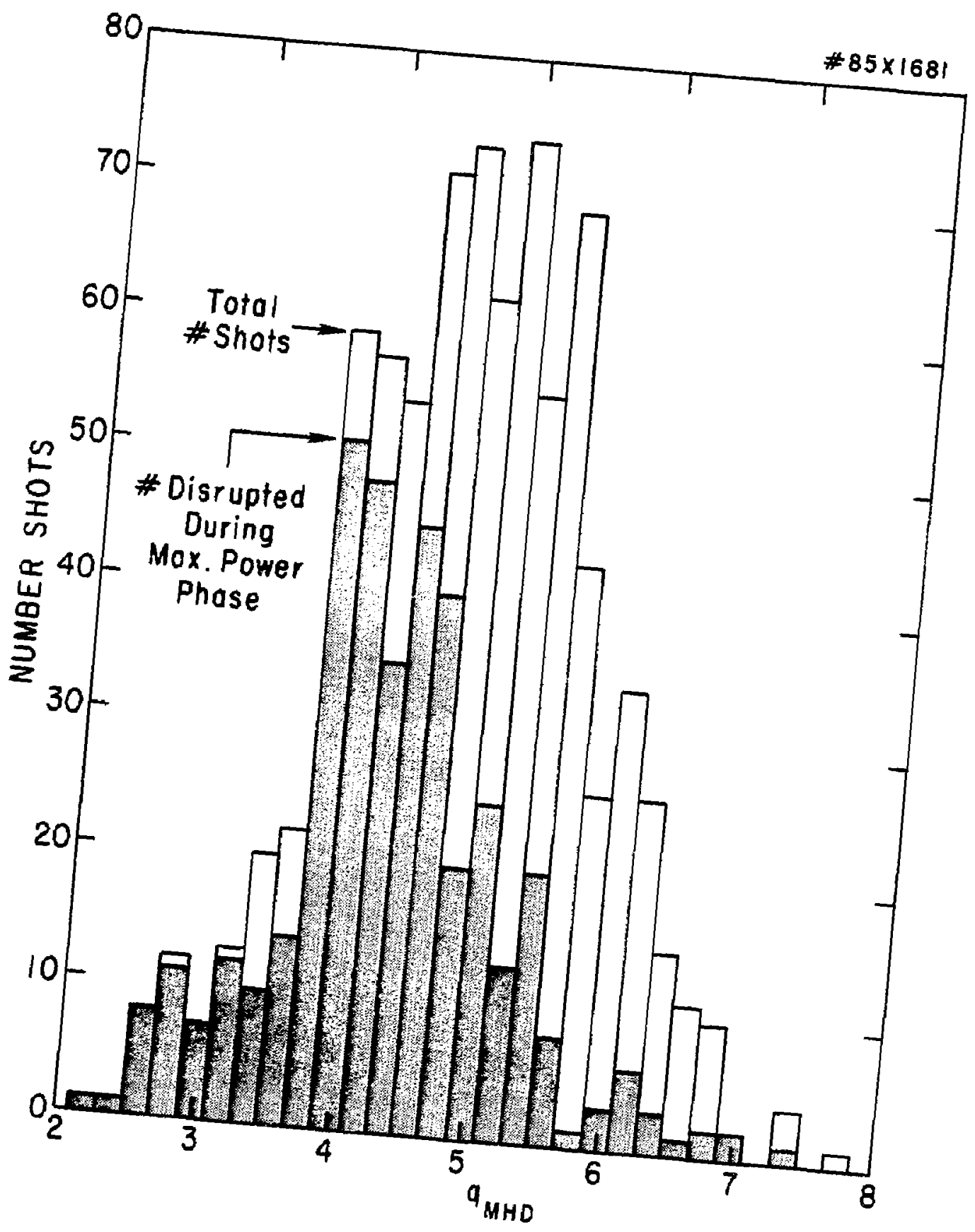

EIgure 3 

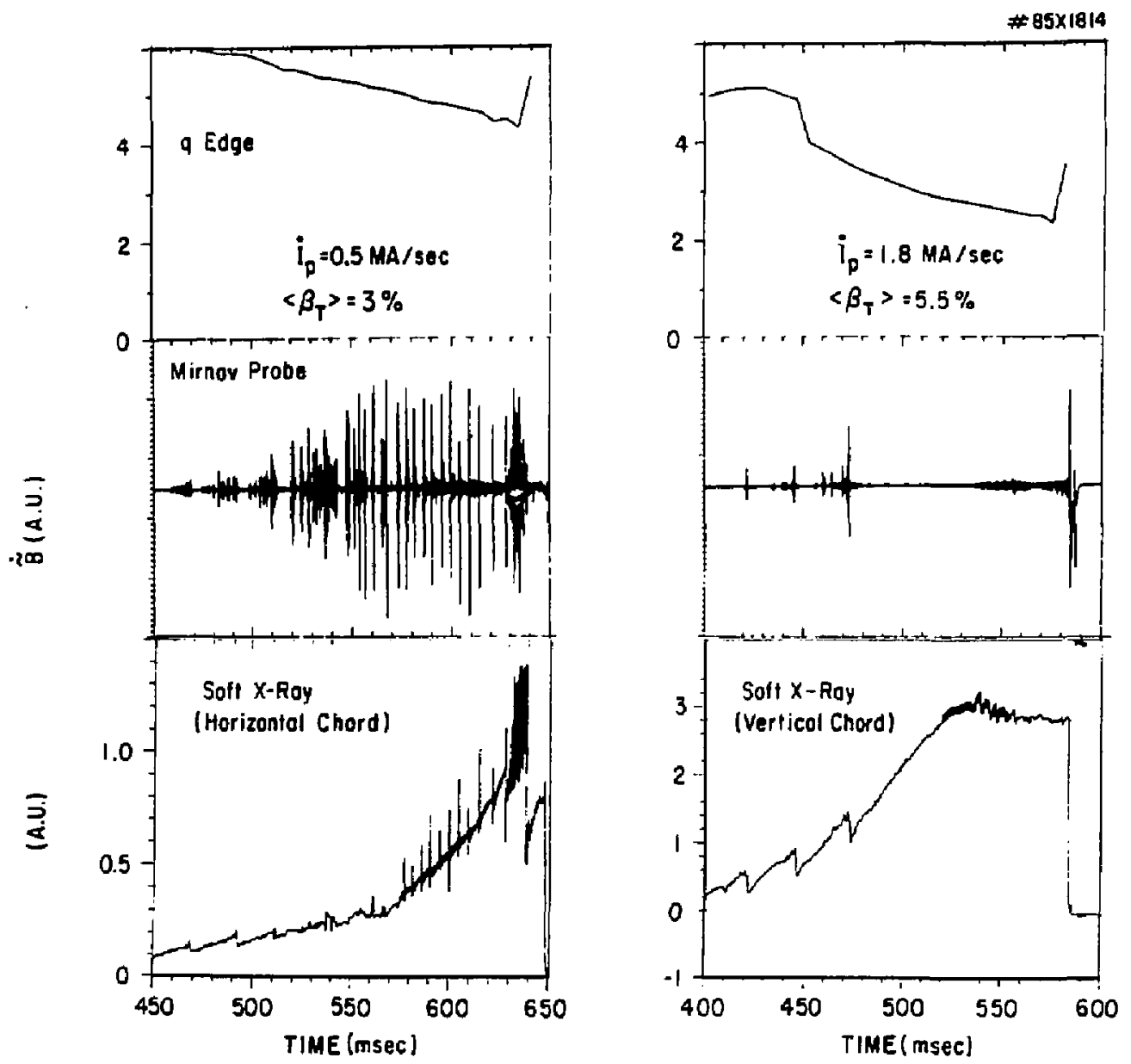

Figure 4 


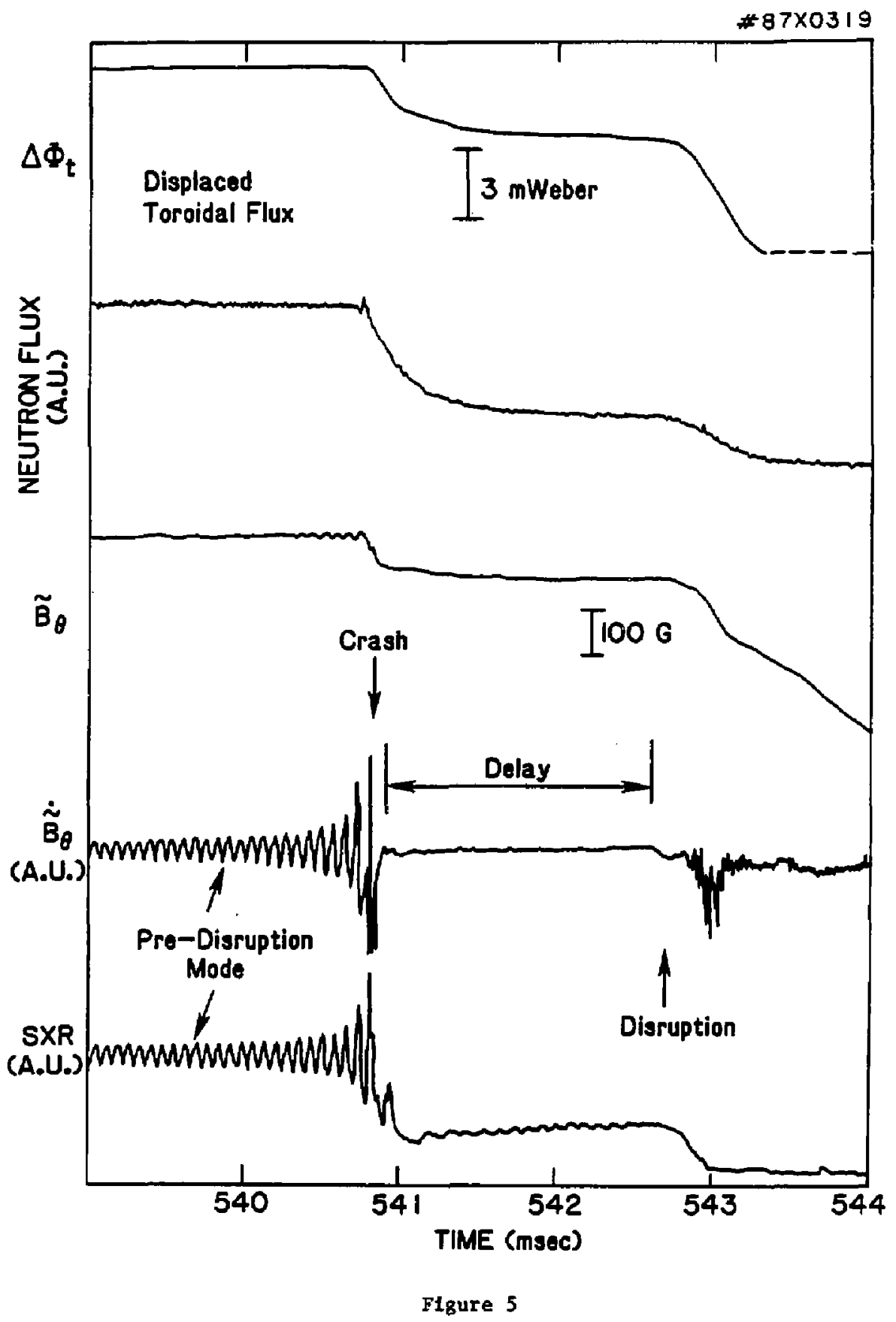


\#87X0318

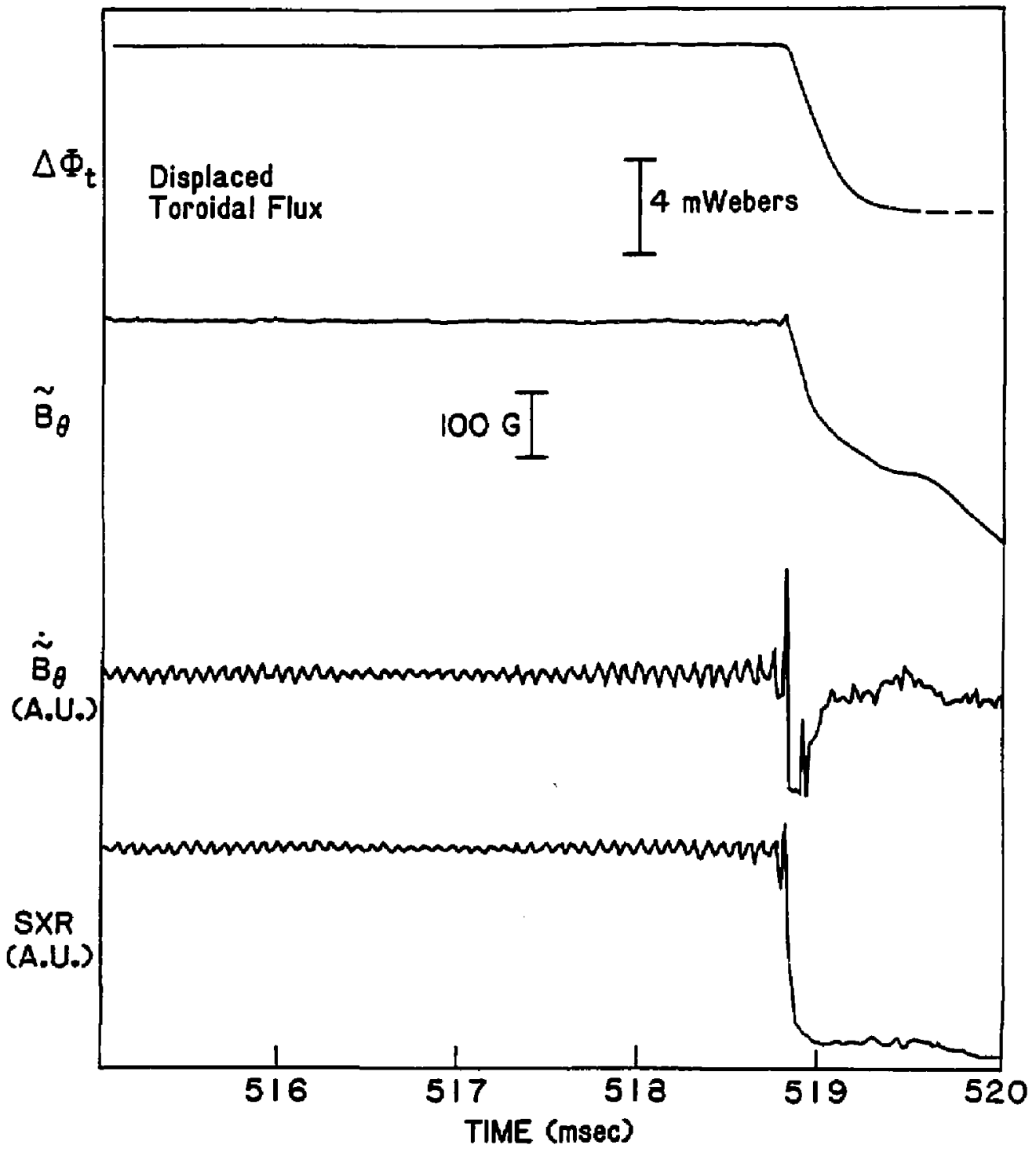

Figure 6 


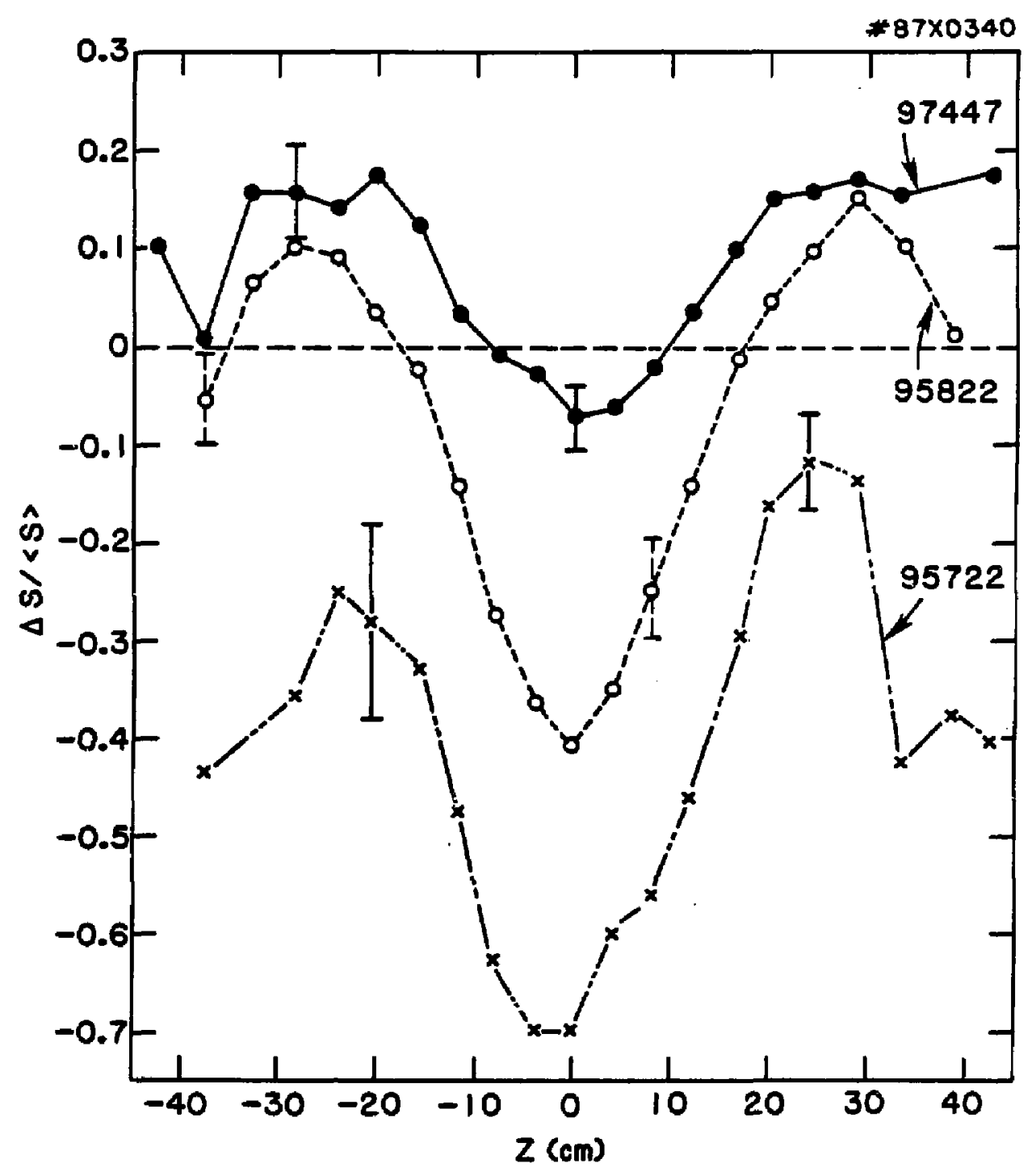

EIgure 7 

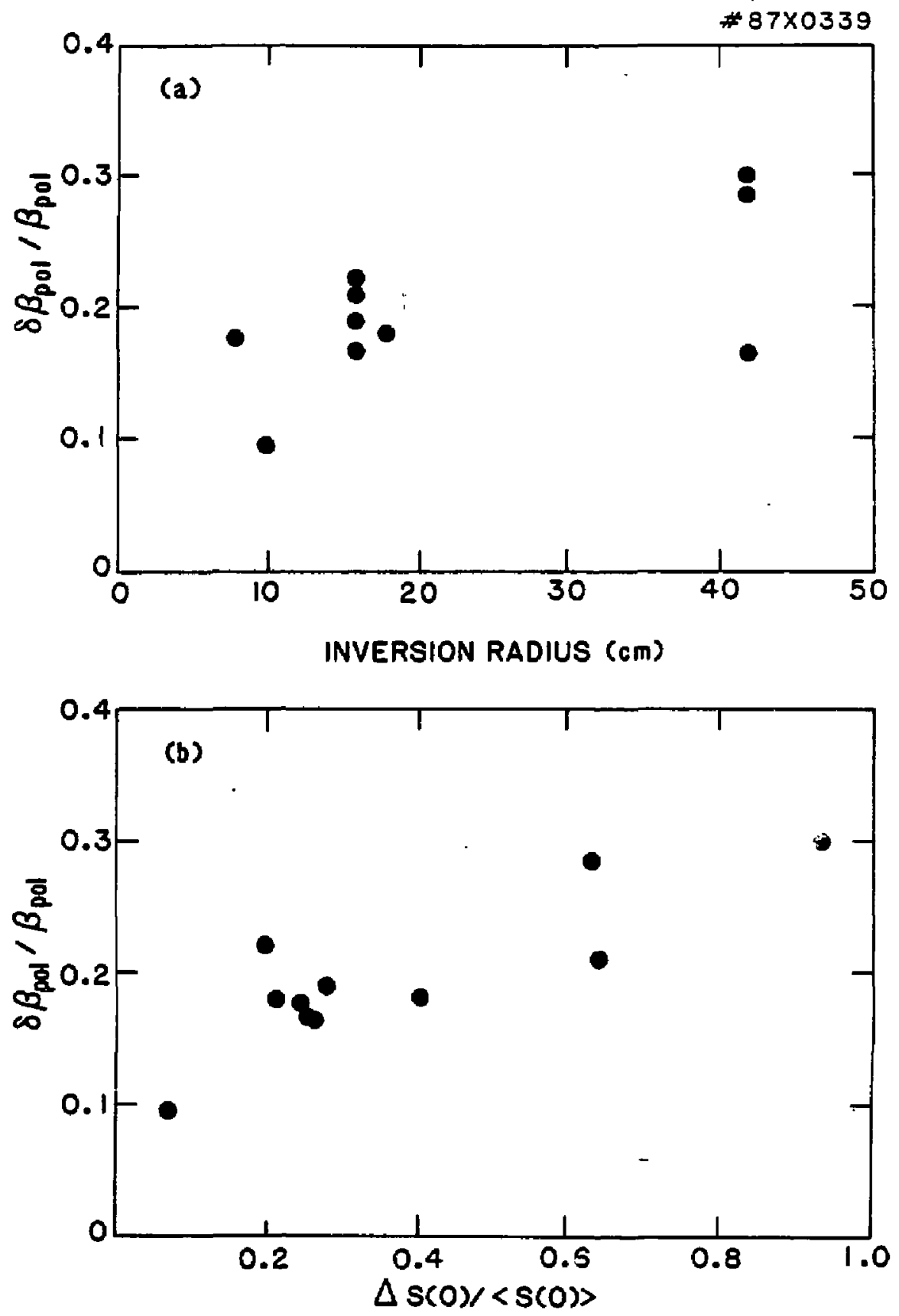

Figure $8 \mathrm{a}, \mathrm{b}$ 


$$
\text { IS }
$$


$\# 87 \times 1015$

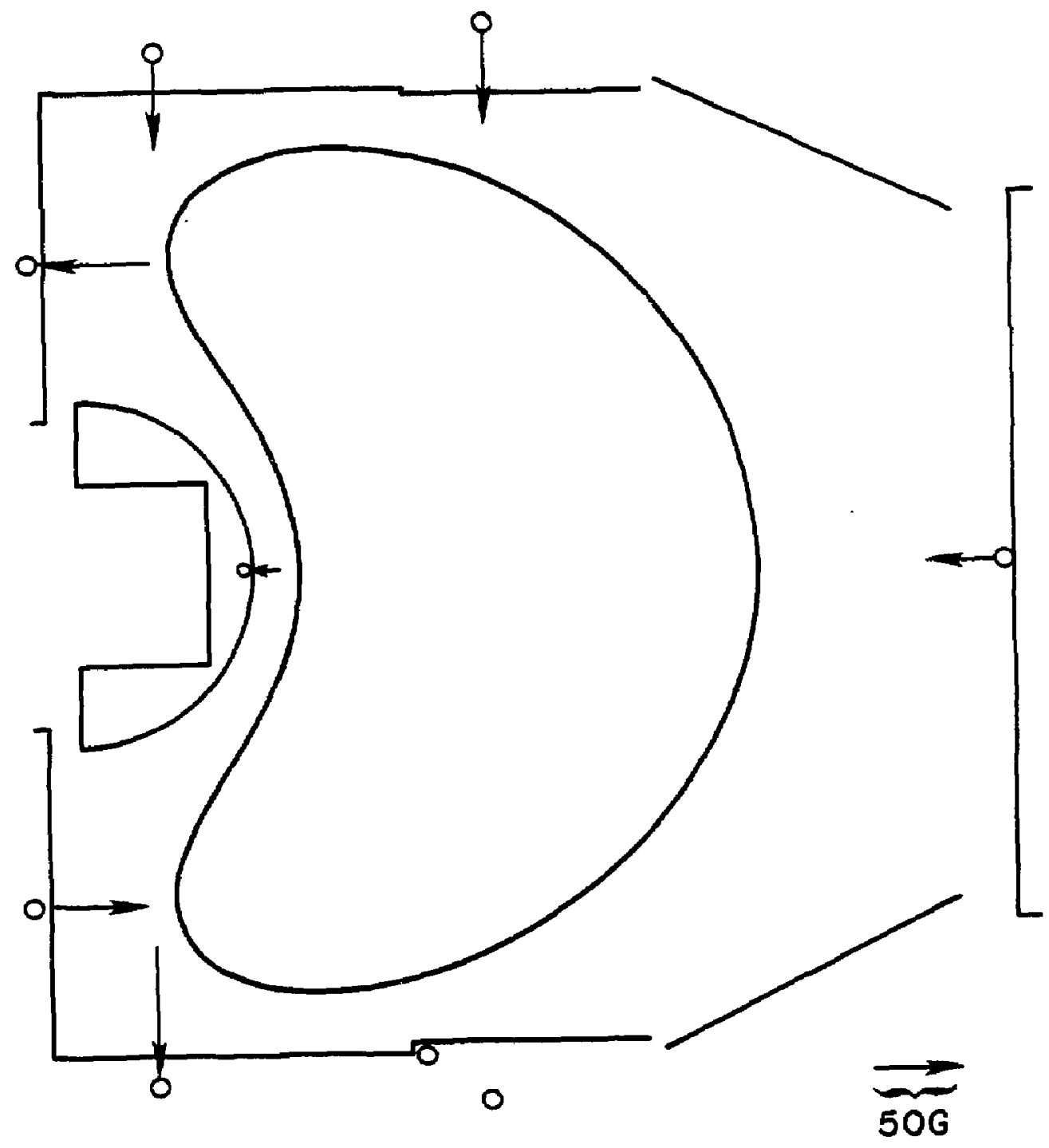

Figure 10 


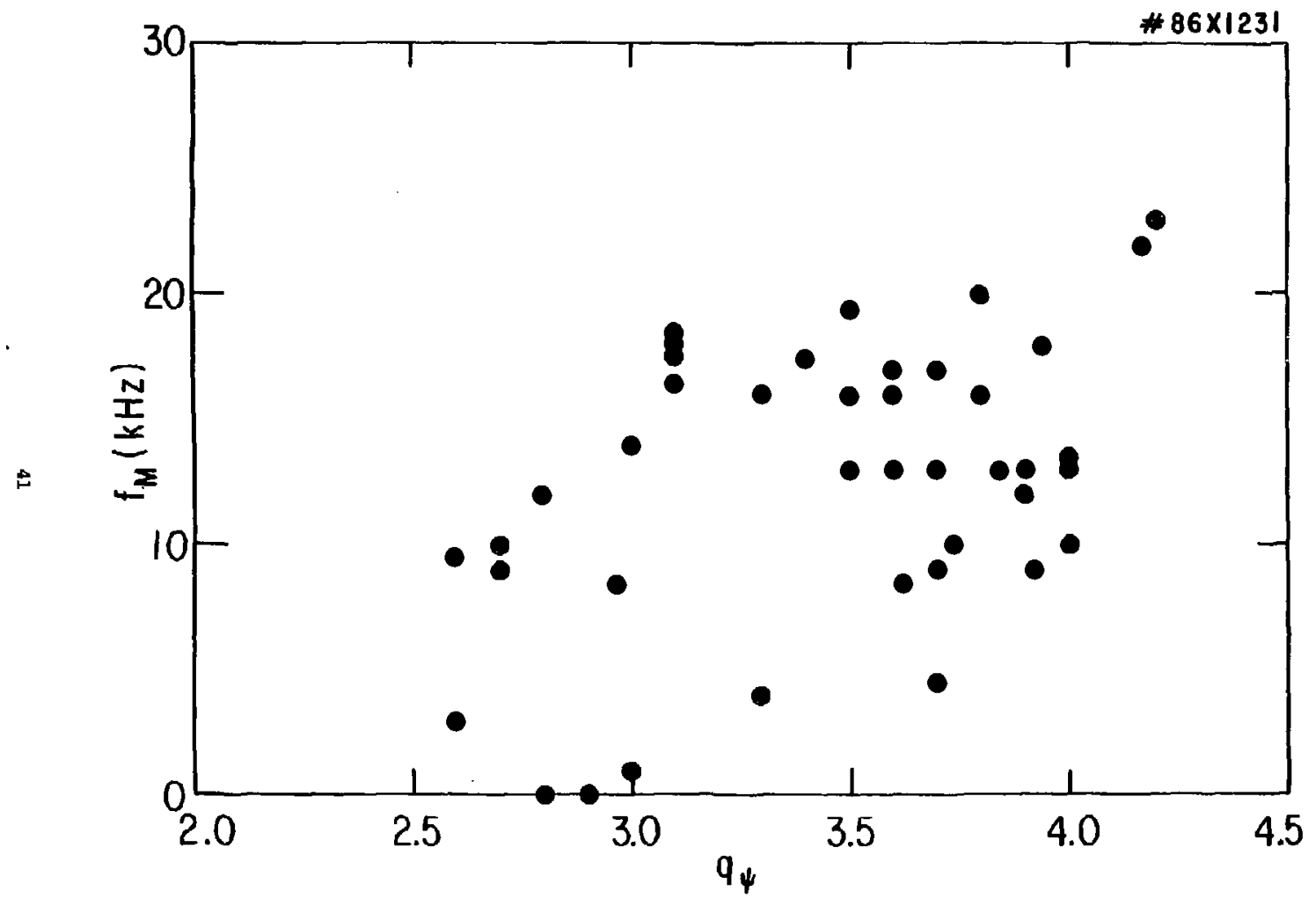

Figure 11 


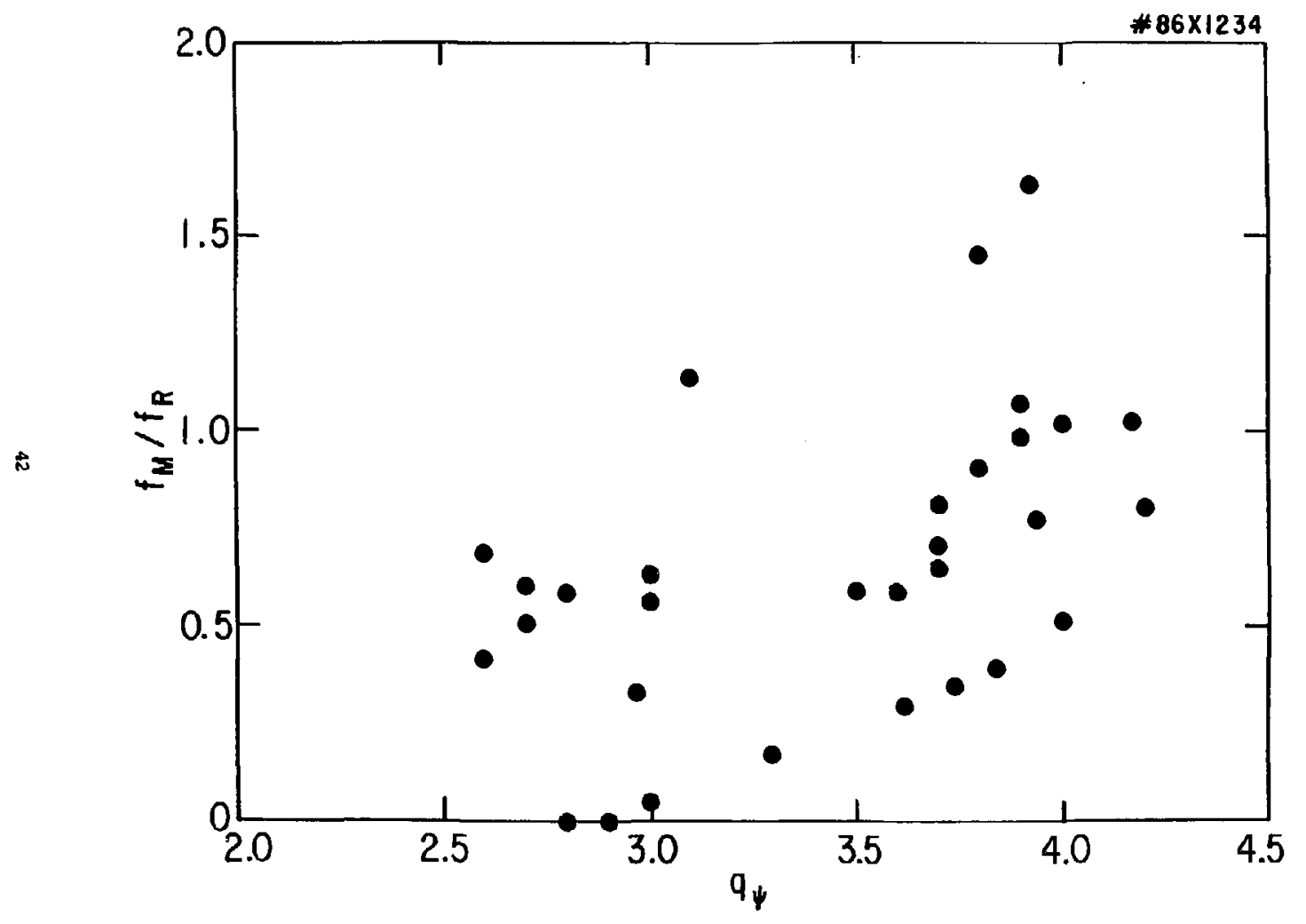

FIgure 12 


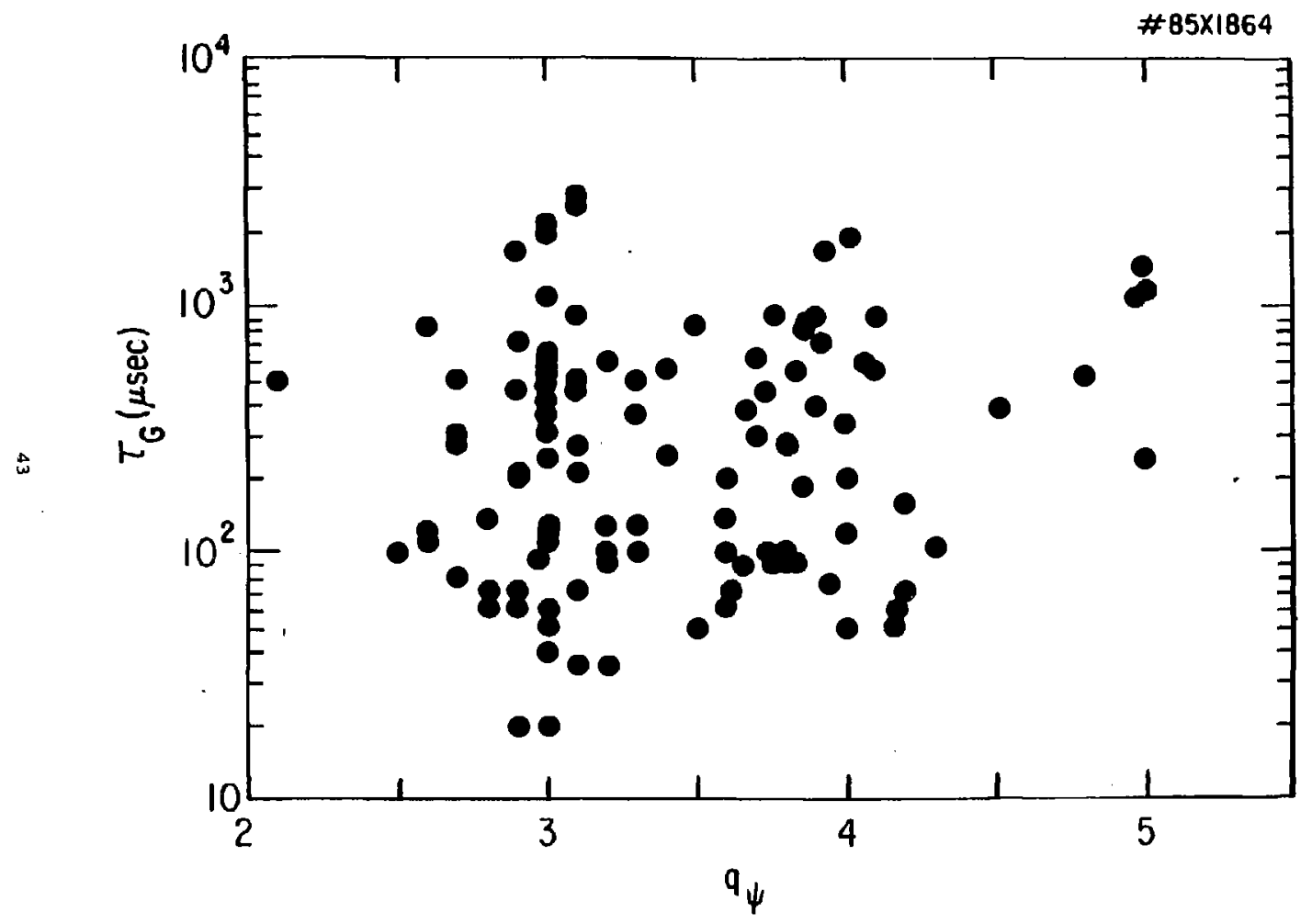

F1gure 13 


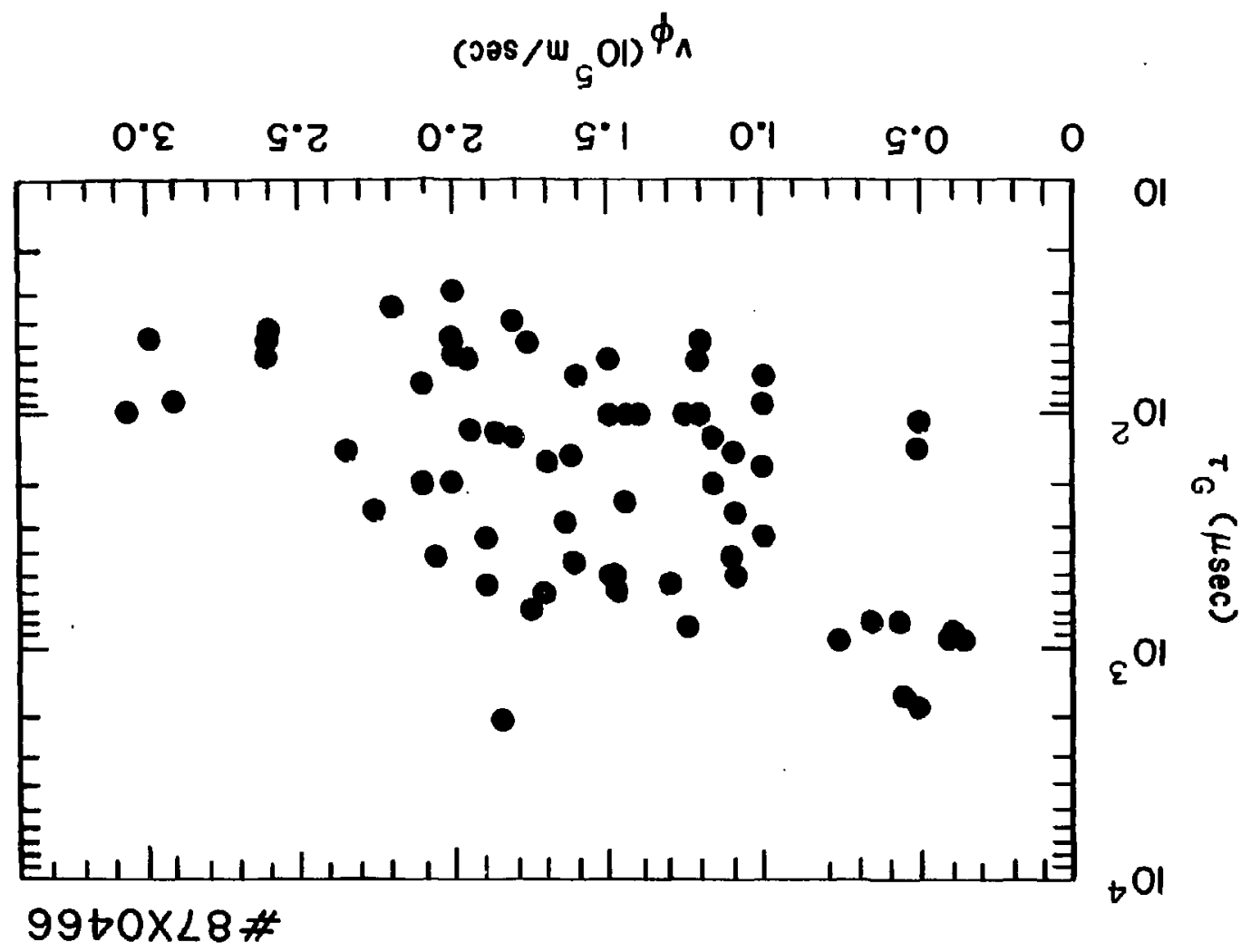



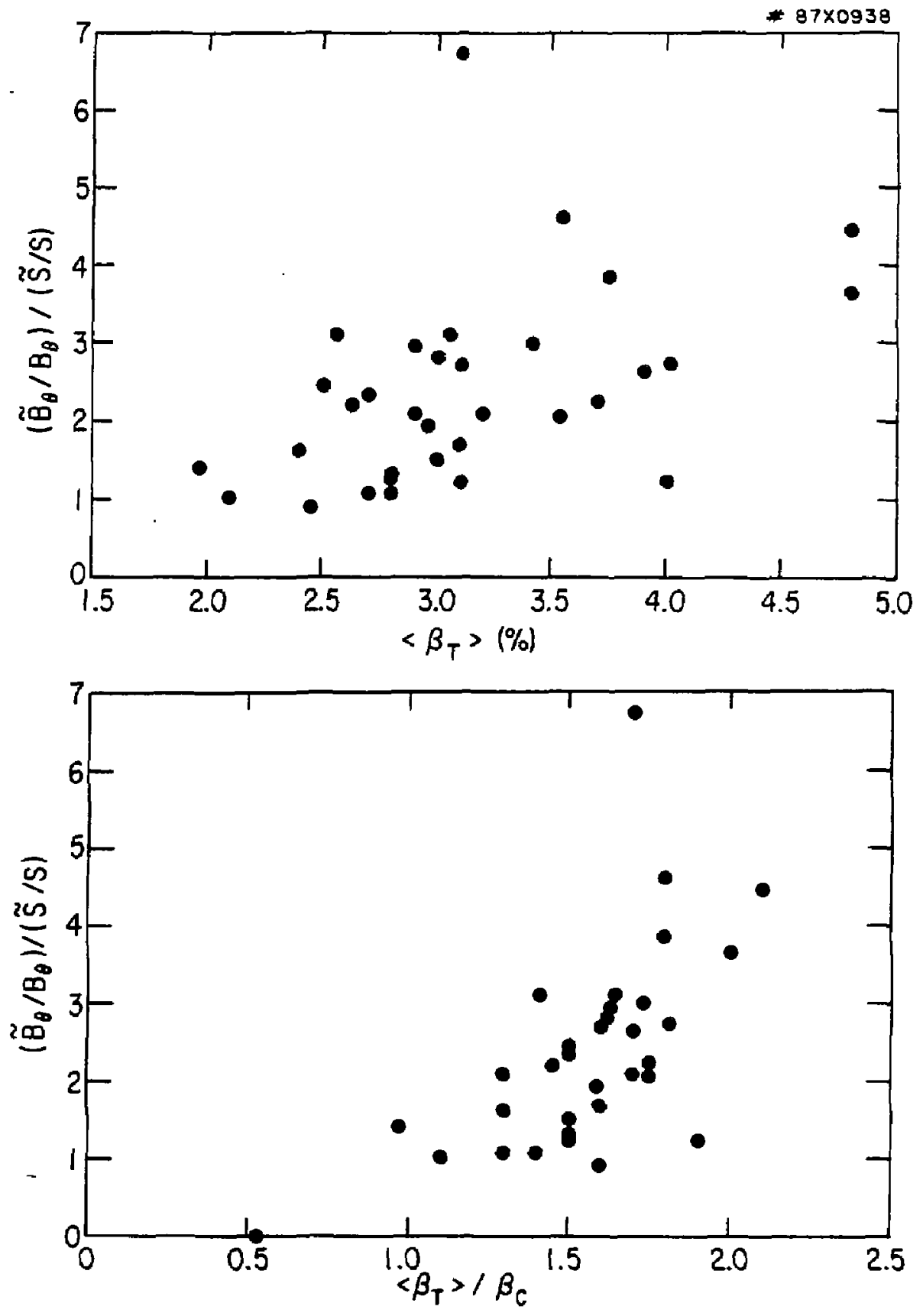

Figure $15 a, b$ 


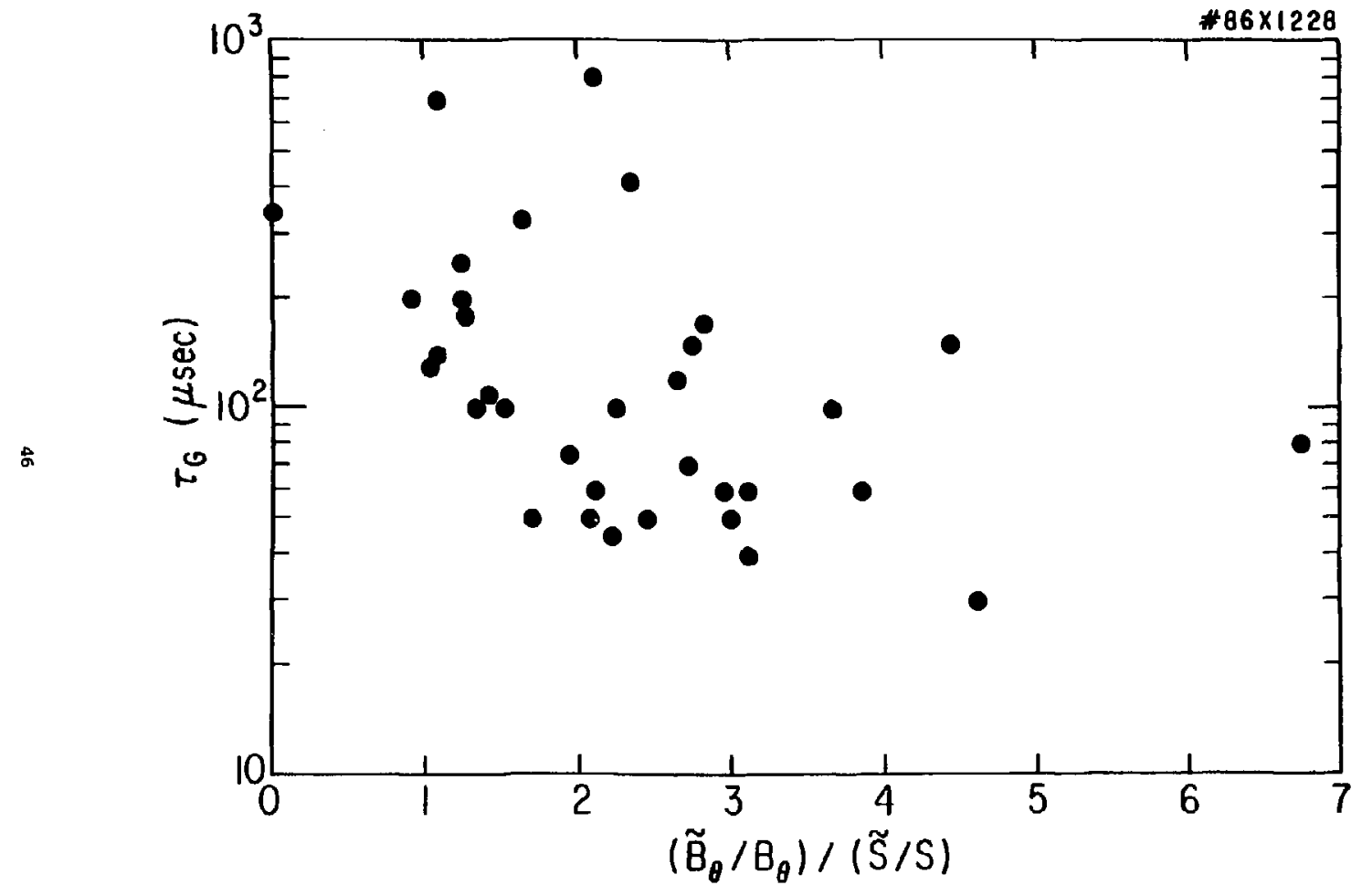

Figure 16 

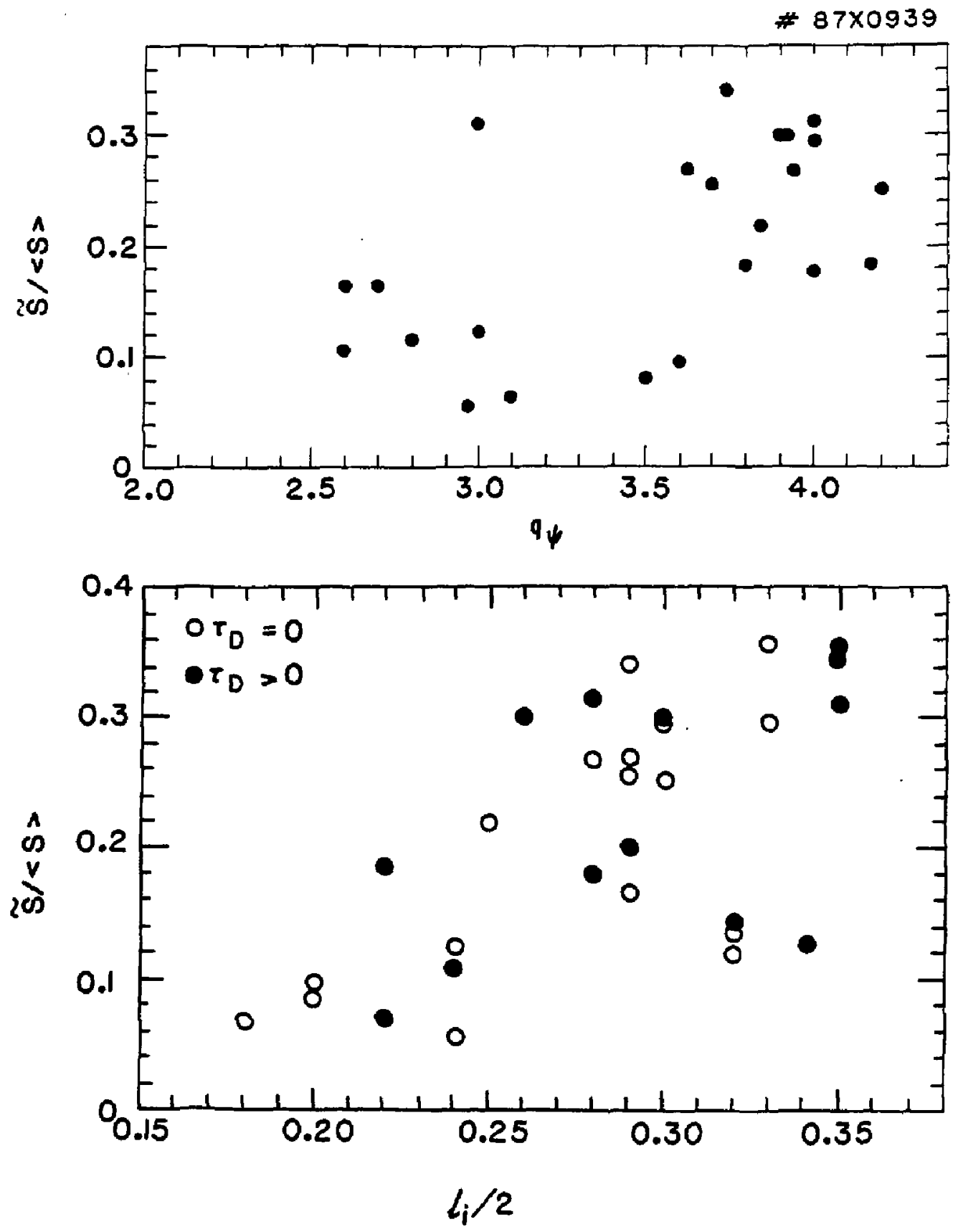

Eigure 17a,b 


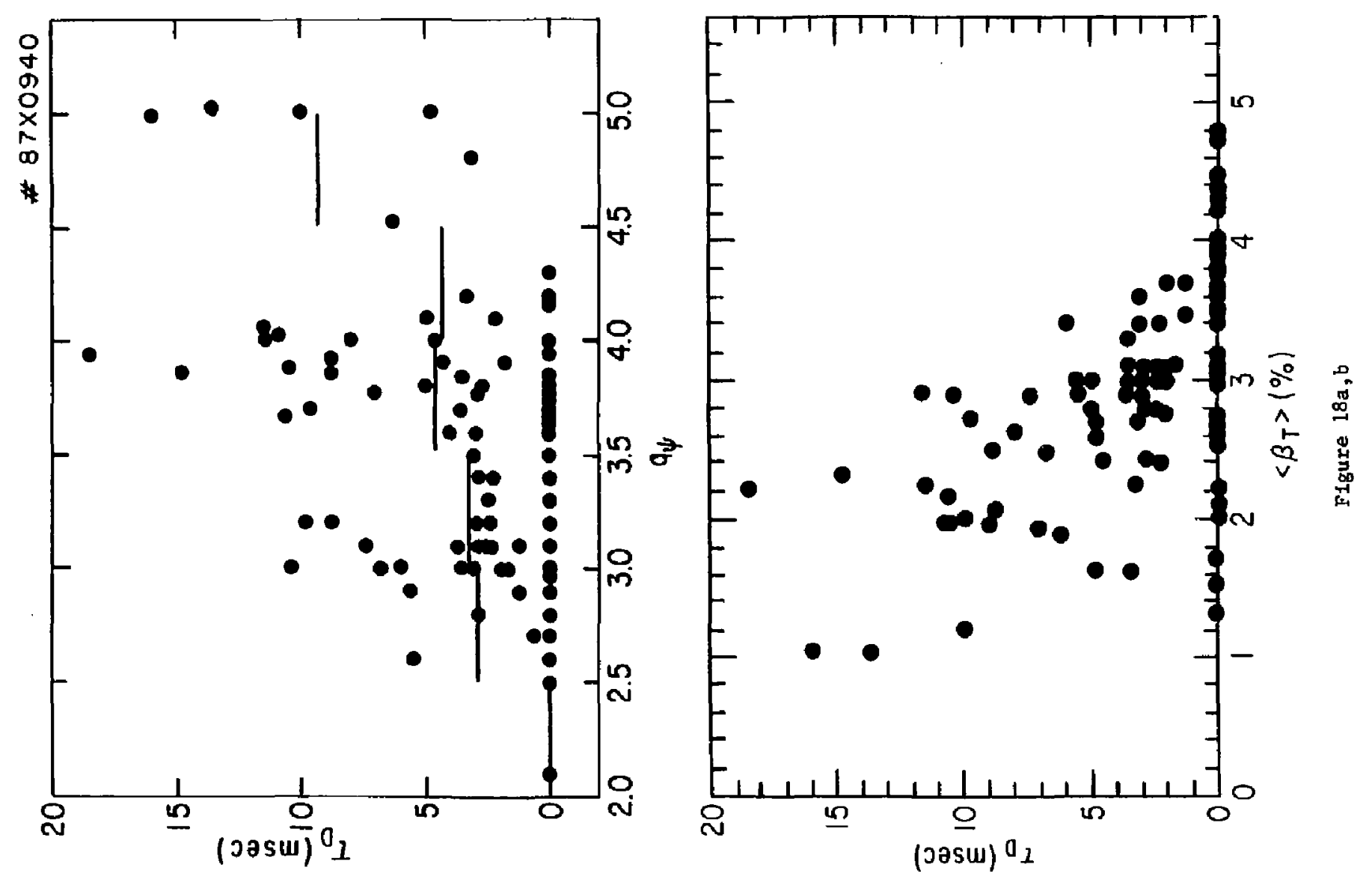




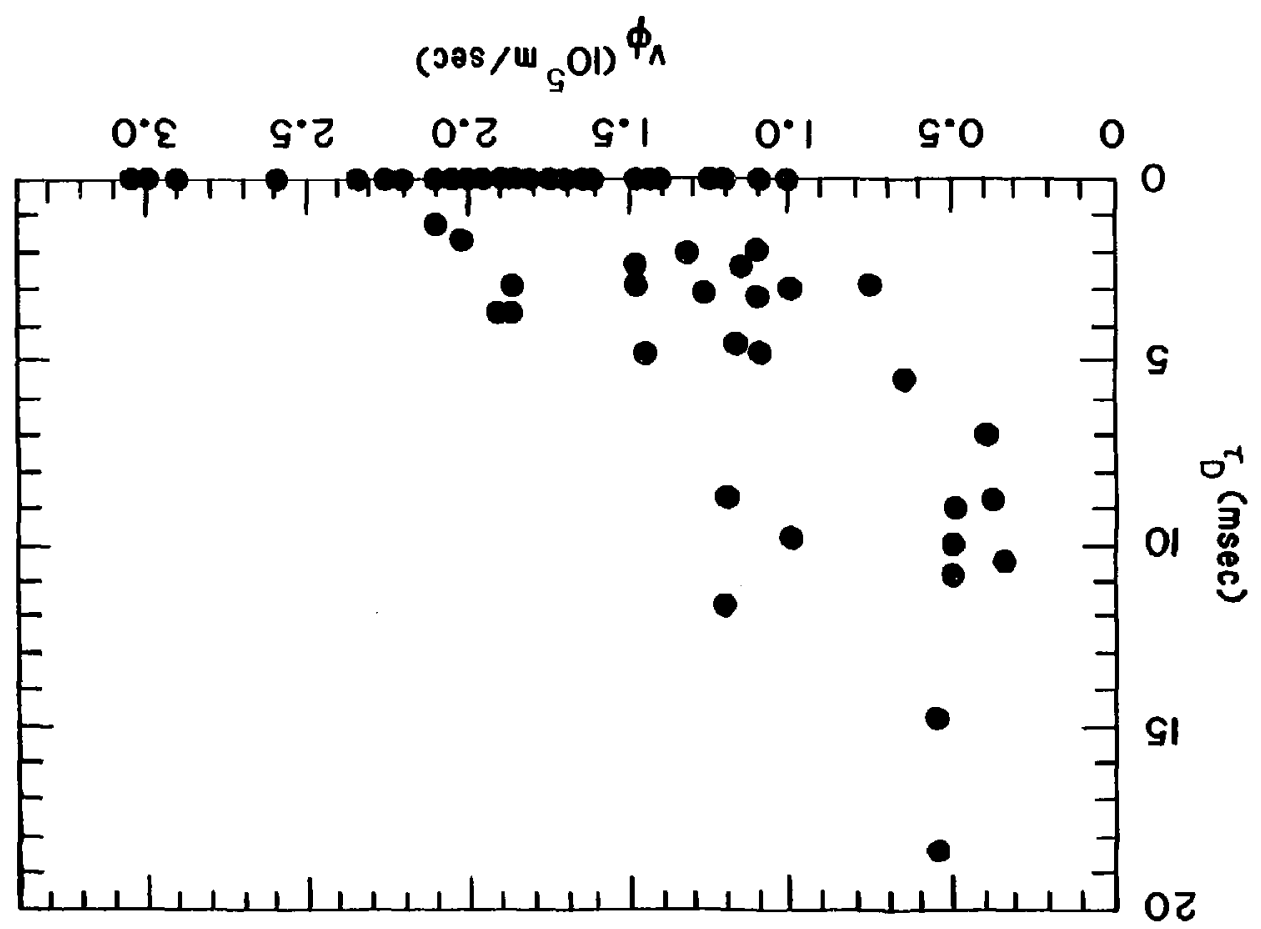
$9960 \times<8$ \# 
Dr. Frank J. Pooloni, Unis of Wollongong, AUSTRALIA Prof. M,H. Erennan, Uniy Sydney, Austalia

Plasma Resoarch Lab., Australian Not. Univ., AUSTRALIA

Prof. I,R. Jones, Flinders Univ., AUSTRALIA

Prof. F. Cap, Inst Theo Phys, AUSTRIA

Prof. M. Heindler, Instifut fur Theoretische Physik, AUSTRIA

- M. Goossens, Astronomisch Instituut, BELGIUA

Ecole Royale Militaire, Lob de Phys Plasmas, BELgIUm

Comission-European, Dg-XII Fusion Prog, BELGIUM

Prof. R. Bouclque, Laboratoriun voor Netuurkunde, BELGIUM

Dr. P.H. Sakanaka, Instltuto Fisica, BRAZIL

Instituto De Posquisos Espociasl-INPE, BRAZIL

Docunents Offlce, Atomic Energy of Canada Limitad, CaNaDh

Dr. M.P. Bachynski, MPE Technologies, Inc., CannDA

Dr. H.M. Skarsgard, University of Saskatcheman, CANADA

Dr. H, Barnard, Univarslity of British Columbio, CANADA

Prof. J. Teichmenn. UnIv. of Montrael, CANADA

Prof. S.R. Sremivasan, University of Calgary, CaNaDA

Prot. Tudor W. Johnston, INRS-Enargle, CAMDA

Dr. C.R. James, UnIv, of Alberto, CANADA

Dr. Poter Lukac, Komenskeho UnIV, CZECHOSLOVAKIA

The Librarian, Culham Laboratory, ENGLAND

The Librarian, Rutherford Appleton Laboratory, ENGLAND

Mrs. 5.A. Hutchinson, JET Library, ENGLArD

C. Mouttat, Lab. de Physique des Milieux lenisés, FRunce

J. Radat, CEN/CADARACHE - Bat 506, FRAACE

Univ. of loannina, Library of Physics Oept. GREECE

Dr. Tom Mul, Acadeny Bluliographic Sar., Hown KONG

Preprint Library. Hungar i an Acadeny of Sefences, HugkeY

- Dr. B. Dasgupta, Saha Inst of Nuel. Phys., INDIA

Dr. P. Kaw, Institute for Plasme Research, InDIA

Dr. Phi tip Rosenau, I srael Inst. Toch, ISPAEL

Librarian, Int'I Ctr Theo Phys, ITALy

Prof. G. Rostagni, Univ DI Padova, ITALY

Miss Clelia De Palo, Assoc EuRATOA-EnEA, ITALY

Biblioteca, Institute di fisica del PIasma, ITALY

Dr. H. Yanato, Toshtbo Res \& Dov, JAPAN

Prof. I. Kawakani, Atomle Enorgy Ros. Institute, JAPAN

Prof. Kyoji Nishikawa, Univ of Hiroshina, JNPAN

Direc. Dept, Large Tokamak Res, JAERI, JAPAN

Prof. Satoshi Itoh, Kyushu University, JAPAN

Rosoarch Info Center, Nagoyo University, JAPAN

Prof. S. Tanaka, Kyoto University, JAPAN

Library, Kyoto University, JAPAN

Prof. Nobuyuki Inowe, University of Tokyo, JAPAN

S. Mori, JAER1, JAPAN

Librarian, Kores Advanced Energy Res. Institute, KOREA

Prof. D.l. Chol, Adv. Inst Sci \& Tach, KOREA

Prot. B.S. Liley, University of Walkato, NEW ZEALAND

Institute of Plasma Physles, PEOPLE's REPU⿴囗IC of CHIMA

Librarian, Institute of Phys., PEOPLE'S REPUBLIC Of CHINA

Library, Tsing Hua University, PEOPLE'S REPUBLIC GF CHINA
Z. Li, Southwest Inst. Physies, PEOPLE's REPUBLIC Of CHINA Prof. J.A.C. Cabral, Inst Superior Teenico, PORTUGAL

Or. Detovian Potrus, AL I CUZA University, ROMANIA

Dr. Johan de villiers, Fusion Studies, AEC, SO AFRICA

Prof. M.A. Hellberg, University of Natal, SO AFRICA

C.I.E.M.A.T., Fusian Div. Library, SPAIN

Or. Lennart Stenflo, University of UMEA, SHEDEN

LIbrary, Royal Inst Toch, SWEDEN

Prof. Hans WI Iheimson, Chalmers Un iv Tech, SWEDEN

Centre Phys des Plasmas, Ecole Polytech Fod, SwITZERLAND

BIbliotheak, Fom-Inst Voor Plasma-Fysica, THE NETMERLANOS

Dr. D.D. Ryutov, Sibarian Acod Sci, USSR

Dr. G.A. El iseav, Kurchatov Institute, USSR

Dr. Y.A. Glukhikh, Inst Electrophysical Apparatus, USSR

Dr. V.T. Tolok, Inst. Phys. Tech. USSR

Or. L.M. Kovrizhnykh, Institute Gen. Physics, USSR

Nuclear Reg. Estadishment, Julich Ltd., W. GERMANY

Bibllothok, Inst. Fur Plasmalorschung, W. GEFMANY

Dr. K. Sehindler, Ruhr Un iversitat Bochum, G. GERMANY

ASOEX Roading Ron, IPP/Max-PI anck-Institut if ur

Plasmaphysik, W. GERMANy

Librarian. Max-Planck Institut, W. GERANY

Prof. R.K. Janev, Inst Phys, YUGOSLAviA 